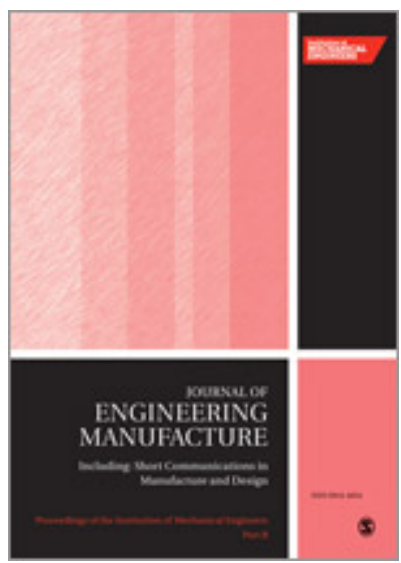

\title{
Green Machining for the Dry Milling Process of Stainless Steel 304
}

\begin{tabular}{|c|c|}
\hline Journal: & Part B: Journal of Engineering Manufacture \\
\hline Manuscript ID & JEM-19-0310.R1 \\
\hline Manuscript Type: & Original article \\
\hline $\begin{array}{l}\text { Date Submitted by the } \\
\text { Author: }\end{array}$ & $\mathrm{n} / \mathrm{a}$ \\
\hline Complete List of Authors: & $\begin{array}{l}\text { Thanh, Nguyen; Duy Tan University, Institute of Research and } \\
\text { Development; Le Quy Don Technical University, Faculty of Mechanical } \\
\text { Engineering } \\
\text { Mia, Mozammel; Ahsanullah University of Science and Technology, } \\
\text { Mechanical and Production Engineering } \\
\text { Dang, Xuan-Phuong; Nha Trang University } \\
\text { Le-Chi, Hieu; University of Greenwich, Faculty of Engineering and } \\
\text { Science } \\
\text { Packianather, Michael; Cardiff University }\end{array}$ \\
\hline Keywords: & $\begin{array}{l}\text { Dry milling, Power factor, Energy consumption, Surface roughness, } \\
\text { Principal component analysis, Radial basis function }\end{array}$ \\
\hline Abstract: & $\begin{array}{l}\text { Dry machining represents an eco-friendly method that reduces the } \\
\text { environmental impacts, saves energy costs, and protects operator } \\
\text { health. This paper presents a multi-response optimization which aims to } \\
\text { enhance the power factor and decrease the energy consumption as well } \\
\text { as the surface roughness for the dry machining of a stainless steel } 304 \text {. } \\
\text { The cutting speed }(\mathrm{V}) \text {, depth of cut }(\mathrm{a}) \text {, feed rate ( } \mathrm{f} \text { ), and nose radius ( } \mathrm{r} \text { ) } \\
\text { were the processing conditions. The outputs of the optimization are the } \\
\text { power factor, energy consumption, and surface roughness. The } \\
\text { relationships between inputs and outputs were established using the } \\
\text { radial basis function models. The experimental data were normalized, } \\
\text { with the use of the grey relational analysis. The principal component } \\
\text { analysis is applied to calculate the weight values of technical responses. } \\
\text { The desirability approach is used to observe the optimal values. The } \\
\text { results showed that the technical outputs are primarily influenced by the } \\
\text { feed rate and cutting speed. The reductions of energy consumption and } \\
\text { surface roughness are approximately } 34.9 \% \text { and } 57.7 \% \text {, respectively, } \\
\text { and the power factor improves around } 28.8 \% \text {, compared to the initial }\end{array}$ \\
\hline
\end{tabular}


process parameter settings. The outcomes and findings of the investigated work can be used for further research in sustainable design and manufacturing as well as directly used in the knowledge-based and expert systems for dry milling applications in industrial practices.

\section{SCHOLARONE ${ }^{m}$ Manuscripts}




\title{
Title Page
}

Article type: Research article

\section{Corresponding author:}

\section{Trung-Thanh Nguyen}

Institute of Research and Development, Duy Tan University, 03 Quang Trung, Da Nang 550000, Vietnam

Faculty of Mechanical Engineering, Le Quy Don Technical University, 236 Hoang Quoc Viet, Ha Noi 100000, Viet Nam

E-mail addresses: nguyentrungthanh6@duytan.edu.vn; trungthanhk21@mta.edu.vn ORCID: 0000-0002-0838-872X

\section{Article title: Green Machining for the Dry Milling Process of Stainless Steel 304}

\author{
Authors: \\ Trung-Thanh Nguyen ${ }^{1,2^{*}}$ Mozammel Mia ${ }^{3}$, Xuan-Phuong Dang ${ }^{4}$, Chi-Hieu Le ${ }^{5}$, Michael \\ Packianather $^{6}$ \\ ${ }^{1}$ Institute of Research and Development, Duy Tan University, 03 Quang Trung, Da Nang \\ 550000 , Vietnam \\ ${ }^{2}$ Faculty of Mechanical Engineering, Le Quy Don Technical University, 236 Hoang Quoc Viet, \\ Ha Noi 100000, Viet Nam \\ ${ }^{3}$ Mechanical and Production Engineering, Ahsanullah University of Science and Technology, \\ Dhaka, Bangladesh \\ ${ }^{4}$ Faculty of Mechanical Engineering, Nha Trang University, Nguyen Đinh Chieu, Nha Trang \\ 57000, Viet Nam \\ ${ }^{5}$ Faculty of Engineering \& Science, University of Greenwich, Chatham, UK \\ ${ }^{6}$ School of Engineering, Cardiff University, Cardiff, UK
}

\section{Keywords:}

Dry milling; Power factor; Energy consumption; Surface roughness; Principal component analysis; Radial basis function. 


\title{
Green Machining for the Dry Milling Process of Stainless Steel 304
}

\begin{abstract}
:
Dry machining represents an eco-friendly method that reduces the environmental impacts, saves energy costs, and protects operator health. This paper presents a multi-response optimization which aims to enhance the power factor and decrease the energy consumption as well as the surface roughness for the dry machining of a stainless steel 304. The cutting speed $(V)$, depth of cut $(a)$, feed rate $(f)$, and nose radius $(r)$ were the processing conditions. The outputs of the optimization are the power factor, energy consumption, and surface roughness. The relationships between inputs and outputs were established using the radial basis function models. The experimental data were normalized, with the use of the grey relational analysis. The principal component analysis is applied to calculate the weight values of technical responses. The desirability approach is used to observe the optimal values. The results showed that the technical outputs are primarily influenced by the feed rate and cutting speed. The reductions of energy consumption and surface roughness are approximately $34.85 \%$ and $57.65 \%$, respectively, and the power factor improves around $28.83 \%$, compared to the initial process parameter settings. The outcomes and findings of the investigated work can be used for further research in sustainable design and manufacturing as well as directly used in the knowledge-based and expert systems for dry milling applications in industrial practices.
\end{abstract}

Keywords: Dry milling; Power factor; Energy consumption; Sustainable Manufacturing; Principal component analysis; Radial basis function. 


\section{Introduction}

In wet machining, liquid coolant is normally used to reduce the temperature of both workpiece and cutting tool, as well as to evacuate chips from the cutting area, with hundreds of thousands of gallons of coolant fluid used per year, causing a lot of money spent and poor environmental impacts ${ }^{1}$. The total cost of the lubrication accounts for $7-17 \%$ of the cutting tool cost, and it is even greater than overhead and labor costs ${ }^{2}$. Fortunately, dry machining is becoming more prevalent, especially in milling, and it is considered as one of the eco-friendly machining processes, with good environmental impacts and cost-effectiveness. With the emerging trends of sustainable design and manufacturing, dry machining is considered as one of the green solutions to enforce environmental protection laws for occupational safety and health regulations; and it is an effective solution for sustainable manufacturing, especially to help to minimize the use of lubricants that cause air and water pollutions.

The improvements in the technical parameters of dry machining processes have been considered by many researchers ${ }^{3-5}$. Fundamentally, the technical outputs of a machining process, including the surface integrity, cutting temperature, and tool life were improved by means of optimization of process parameters (or machining factors) ${ }^{6,7}$. Babu et al. ${ }^{8}$ analyzed the surface roughness and vibration for the orthogonal milling. The temperature variations in the workpiece and cutting tool were explored for the dry machining of Inconel $718^{9}$. The surface integrity was improved for milling processes of the Al- $\mathrm{Zn}-\mathrm{Mg}-\mathrm{Cu}$ alloy ${ }^{10}$, aluminum ${ }^{11}$, Ti-6Al-4V alloy ${ }^{12}$, and the hard turning of AISI $52100^{13}$. The grey relational analysis (GRA) was applied to achieve optimum inputs that maximize the surface properties, energy criteria, and production rate ${ }^{14}$. Krolczyk et al. ${ }^{15}$ found that a longer tool life can be obtained under dry cutting compared to the lubricant condition. Additionally, Baowan et al. ${ }^{16}$ revealed that the surface roughness and tool life were significantly influenced by the cutting angle and tools. Pham et al. ${ }^{17}$ stated that the tool-chip contact length, the workpiece vibration, and the surface roughness were increased with 
increasing cutting depth and feed rate for the dry milling of A6061 aluminum alloy. Jahan et al. 18 concluded that the mid-level of the feed and depth of cut could be used to decrease the tool wear and surface roughness in the milling of polycarbonates. Mia and Dhar ${ }^{19}$ emphasized that specific cutting energy was influenced favorably by the increase in cutting speed.

Recently, the trade-off between energy consumption, surface integrity, and productivity has been explored in the works of literature. As part of trade-off among responses, Khan et al. ${ }^{20}$ conducted multi-response optimization for the face milling of steel to attain improved surface quality, material removal quantity and cutting energy. From conventional statistics-based approaches to advanced neural and evolutionary algorithms are continually used for computation of the best trade-off. For instance, Mia et al. ${ }^{21}$ performed intelligent optimization of the machining process from the perspective of smart manufacturing. On the other side, the response surface methodology (RSM) was applied to analyze the impacts of input process parameters on energy consumption ${ }^{22}$, power consumption, cutting force, and surface roughness ${ }^{23}$. Similarly, the multi-objective optimizations were performed in order to minimize the energy consumption in the dry turning of stainless steel ${ }^{24}$. Zhang et al. ${ }^{25}$ proposed the relations between the process parameters on the total processing time, specific energy consumption, and carbon emissions. Song et al. ${ }^{26}$ developed a new model to predict the machining forces in multi-axis milling. The impacts of the process parameters on the machining energy for the micro-milling composites were analyzed by Kuram ${ }^{27}$. The stress field distribution on a cutter in the milling of titanium alloy was analyzed based on the empirical models of the milling force and the contact area between the cutter and the chip ${ }^{28}$. As a result, various approximation methods and optimizing techniques were used to render the relationship between the processing conditions and output criteria and to find the optimum process parameter. The different performances measured were optimized and improved by means of the optimum factors. However, the drawbacks of the published works can be listed as bellow: 
The outputs response parameters of the machining process such as the energy consumption, cutting forces, quality of the machined part, and tool life were widely considered in the published works. Practically, the power factor (the ratio of the active power consumption and the apparent power) is necessary to be considered as an important technical parameter for maximizing energy efficiency.

The stainless steels are widely used for manufacturing components used in the automotive and aerospace industry as well as in medical sector ${ }^{29,30}$. Unfortunately, it is difficult to machine this material due to work hardening, high surface roughness, high tool wear, and low production rate. Furthermore, machining stainless steel is required higher energy consumption because of low thermal conductivity and high heat capacity. Therefore, it is necessary and important to develop optimization models to support the decision-making process and predicting the values of the power factor (PF), energy consumption (EC), and surface roughness $\left(\mathrm{R}_{\mathrm{a}}\right)$ for dry machining applications.

As a result, a few studies have focused on the process parameters optimization for improving the technological performances of the dry machining processes. However, optimizations of the machining process parameters and cutting tool's geometry for simultaneous improvements of the power factor (PF), energy consumption (EC), and surface roughness $\left(\mathrm{R}_{\mathrm{a}}\right)$ have not been considered in the aforementioned works; and these were investigated and presented in details in this study. Furthermore, the optimal results directly selected from experimental data may fall into the trap of local optimization.

In order to overcome the above-mentioned drawbacks of the published works, in this study, a multiple-response optimization of machining parameters of the dry milling process, for the case of stainless steel 304, was considered and applied; it aims to simultaneously enhance the power factor $(\mathrm{PF})$, energy consumption $(\mathrm{EC})$, and surface roughness $\left(\mathrm{R}_{\mathrm{a}}\right)$. In addition, it was well-recognized that the effects of machining process parameters as the inputs for the 
optimization may contribute to the variations of the measured performances of the machining operation. Therefore, an effective approach for modeling dry milling behavior and optimizing the processing factors in terms of improving working performances is still a significant contribution.

The rest of the paper is organized as follows. Section 2 presents the methods used for the proposed optimization problems. Section 3 presents the experimental setting and measurements. Section 4 presents results and discussions. Finally, summaries and conclusions are presented in Section 5 .

\section{Methods}

\subsection{Optimizing issue}

The power factor (PF) is defined as the ratio of the active power consumption (APC) to the apparent power (APP), as shown in Eq. 1.

$$
P F=\frac{A P C}{A P P}=\frac{A P C}{\sqrt{A P C^{2}+R P^{2}}}
$$

The power transmitted from the electrical source to the device contains two subcomponents, including the active power and reactive power (RP). The active power characterizes the useful capacity of the device. Reactive power does not produce any productive work but it is necessary for energy transformation. Reactive power significantly creates a magnetic field for transferring electrical energy into other forms of energy. The apparent power is the vector sum of the active power and reactive power. The higher the power factor, the higher the active power and the device will produce more useful power. In fact, the power factor depends on a load of electrical equipment ${ }^{31}$. For a milling machine, most of the sub-systems have a variable speed and variable operating load, which leads to the changes in the power factor. The variations of machining conditions, such as the cutting speed, feed, depth of cut, nose radius, lubrication 
conditions, and workpiece materials, may cause the variable loads; hence the power factor changes. Therefore, when considering the power consumption of a machining process, the selection of relevant machining conditions to enhance the power factor is always necessary and important.

The average value of the power factor is calculated at the fifteen positions over the cutting time. Here, PF is computed using Eq. 2.

$$
P F=\frac{1}{n} \sum_{i=1}^{n} P F_{i}
$$

where $\mathrm{PF}_{\mathrm{i}}$ and $\mathrm{n}$ are the power factor at the i position and the total measured point, respectively.

Figure 1 presents a typical total energy consumed in a machine tool that can be divided into four components, including the setting energy, air cutting energy, cutting energy, and tool changing energy. Practically, the energy consumed for setting, air cutting, and tool changing times can be considered as constant values due to their less dependence on processing conditions (machining process parameters: cutting speed, depth of cut, feed rate, and nose radius). Therefore, the energetic objective in this work focuses on energy consumption in the cutting stage which is effectively used to remove the material from the workpiece. In this study, the energy consumption (EC) in cutting time is calculated using Eq. 3:

$$
E C=P_{c} \times t_{c}
$$

where $\mathrm{P}_{\mathrm{c}}$ and $\mathrm{t}_{\mathrm{c}}$ denote the power consumed and the cutting time, respectively.

Table 1 presents the processing inputs, including the cutting speed $(V)$, depth of cut (a), feed rate $(f)$, and nose radius $(r)$ for a multi-response optimization, which aims to enhance simultaneously the power factor and decrease the energy consumption and surface roughness in the dry machining. The levels of the processing inputs are determined based on the common values used in the milling processes of the automotive components and verified by cutting tool's handbooks. 


\subsection{Optimizing framework}

The systematic optimization procedure is shown in Fig. 2, including 5 sequential steps presented as follows:

Step 1: The machining runs are conducted according to the experimental matrix generated by the Box-Behnken method (BBM) ${ }^{32}$. BBM is chosen due to an acceptable balance between predictive accuracy and economy. The Box-Behnken method is an effective method, which combines a two-level factorial design. Three required levels of each factor are "1", “0”, and " +1 ", which present the low, middle and high levels. The number of design points is placed on the midpoints of the edges and the center of the block. BBM is more efficient than the other techniques, such as central composite and full factorial designs due to a lower number of experiments, which significantly contribute to experimental costs and time. The full factorial designs are costly in terms of real-machining experiments when the factor number is higher than 2. Moreover, BBM does not present the parameter combinations at their highest or lowest levels. The experiments are avoided to perform at extreme conditions, which may lead to unsatisfactory results.

Step 2: The PF, EC, and $\mathrm{R}_{\mathrm{a}}$ models are then developed with respect to process parameters using the RBF approximate approach.

Step 3: Normalization of the experimental data using the GRA ${ }^{33}$.

The normalized value for the response with the "smaller-the-better" characteristic is calculated using Eq. 4.

$$
x_{i}^{*}(k)=\frac{\max x_{i}(k)-x_{i}(\mathrm{k})}{\max x_{i}(k)-\min x_{i}(\mathrm{k})}
$$

The normalized value for the response with the "higher-the-better" characteristic is computed with the help of Eq. 5.

$$
x_{i}^{*}(k)=\frac{x_{i}(k)-\min x_{i}(\mathrm{k})}{\max x_{i}(k)-\min x_{i}(\mathrm{k})}
$$


where $x_{i}(k)$ denotes the actual value. Additionally, $\max x_{i}(k)$ and $\min x_{i}(k)$ are the maximum and minimum values of the response, respectively.

The deviation sequence $\Delta_{i}(k)$ is calculated by applying Eq. 6 .

$$
\Delta_{i}(k)=\left|x_{0}^{*}(k)-x_{i}^{*}(k)\right|
$$

The value of the grey relation coefficients $\xi_{i}(k)$ for each response is calculated according to Eq. 7.

$$
\xi_{i}(k)=\frac{\Delta_{\min }+\zeta^{*} \Delta_{\max }}{\Delta_{i}(k)+\zeta^{*} \Delta_{\max }}
$$

where $\Delta_{\max }$ and $\Delta_{\min }$ are the maximum and minimum values of $\Delta_{i}(k)$, respectively. $\xi$ denotes the distinguishing factor.

Step 4: Determining the weight values of performances using the principal component analysis (PCA).

The correlation coefficient from the grey relation coefficient is calculated using Eq. 8 .

$$
R_{j l}=\left[\frac{\operatorname{Cov}\left(x_{i}(j), x_{i}(l)\right)}{\sigma x_{i}(j)^{*} \sigma x_{i}(1)}\right], \mathrm{j}=1,2, \ldots \mathrm{m}, 1=1,2, \ldots \mathrm{n} .
$$

where $x_{i}(j)$ and $\operatorname{cov}\left(x_{i}(j), x_{i}(l)\right)$ are the grey relational coefficient and the covariance of the response, respectively. Additionally, $\sigma x_{i}(j)$ and $\sigma x_{i}(l)$ are the standard deviations of the response, respectively. The eigenvalues and consequent eigenvectors are determined by applying Eq. 9 .

$$
\left(R-\lambda_{k} I_{m}\right) \mathrm{V}_{i k}=0
$$

where $\lambda_{k}, V_{i k}$, and $I_{m}$ represent the eigenvalue, the eigenvector, and the identity matrix, respectively. Therefore, the principal component is obtained using Eq. 10.

$$
Y m k=\sum_{i=1}^{n} x_{m}(i) V_{i k}
$$

where $x_{m}(i)$ and $Y_{m k}$ are the normalized response variable and the principal component, respectively.

Step 5: Determining the optimal parameters using the desirability approach (DA). 
The DA is applied to transform the response $\mathrm{y}_{\mathrm{i}}(\mathrm{x})$ into an individual desirability function $d_{i}\left(0 \leq d_{i} \leq 1\right)$ for achieving the desired value. The value of $\mathrm{d}_{\mathrm{i}}$ lies between 0 and 1 , when $d_{i}=$ ' 1 '. It indicates that the ideal response is achieved. The optimal results of the response are adjusted with different weight values. The targets are combined into the desirability function $(D)$ for multi-objective and processing factors. The optimal factors are determined based on the maximum value of the desirability function.

The $d_{i}$ is calculated with respect to the maximizing goal, as shown in Eq. 11 .

$$
d_{i}=\left\{\begin{array}{c}
0, Y_{i} \leq L_{i} \\
\left(\frac{Y_{i}-L_{i}}{H_{i}-L_{i}}\right)^{w}, L_{i}<Y_{i}<-H_{i} \\
1, \mathrm{Y}_{i} \geq H_{i}
\end{array}\right.
$$

The $d_{i}$ is calculated with respect to the minimizing goal, as shown in Eq. 12 .

$$
d_{i}=\left\{\begin{array}{c}
0, Y_{i} \leq L_{i} \\
\left(\frac{H_{i}-Y_{i}}{H_{i}-L_{i}}\right)^{w}, L_{i}<Y_{i}<-H_{i} \\
1, Y_{i} \geq H_{i}
\end{array}\right.
$$

The $d_{i}$ is calculated with respect to the target, as shown in Eq. 13.

$$
d_{i}=\left\{\begin{array}{l}
\left(\frac{Y_{i}-L_{i}}{T_{i}-L_{i}}\right)^{w 1}, L_{i}<Y_{i}<T_{i} \\
\left(\frac{Y_{i}-H_{i}}{T_{i}-H_{i}}\right)^{w 2}, T_{i}<Y_{i}<H_{i} \\
0, \text { otherwise }
\end{array}\right.
$$

The $d_{i}$ is calculated with respect to the range, as shown in Eq. 14 .

$$
d_{i}=\left\{\begin{array}{l}
1, L_{i}<Y_{i}<H_{i} \\
0, \text { otherwise }
\end{array}\right.
$$

where $L_{i}, H_{i}, T_{i}$, and $w_{i}$ are the low, high, target, and weight values of the $i_{t h}$ response, respectively.

The value of the desirability function of the response is calculated by means of Eq. 15 .

$$
D=\left(\begin{array}{c}
N \\
\Pi d_{i}^{r_{i}} \\
i=1
\end{array}\right)^{1 / \sum r_{i}}
$$

where $N$ is the number of the measured responses. 


\subsection{Radial Basis Function model}

RBF (radial basis function) is one kind of neural networks using a hidden layer of radial units and an output layer of linear units, which is applied to interpolate the data points. RBF approximations are characterized by the reasonably fast training and compact networks. They are useful in approximating a wide range of nonlinear spaces. The RBF is expressed as a formula in Eq. $16^{34}$.

$$
F(x)=\sum_{i=1}^{n} \lambda_{i} \phi\left(\left(x-x_{i}\right)+b x+C\right.
$$

where $\gamma$ is a positive constant. $\lambda_{i}, b$, and $c$ are the parameters to be determined, respectively, which are obtained by Eq. $17 \& 18$ in the matrix form.

$$
\begin{gathered}
{\left[\begin{array}{cc}
\phi & P \\
P^{T} & 0
\end{array}\right]\left\{\begin{array}{l}
\lambda \\
a
\end{array}\right\}=\left\{\begin{array}{l}
F \\
0
\end{array}\right\}} \\
P=\left\{\begin{array}{cc}
1 & X_{1}^{T} \\
1 & X_{2}^{T} \\
\cdot & \cdot \\
\cdot & \cdot \\
\cdot & \cdot \\
1 & X_{n}^{T}
\end{array}\right\}, \lambda=\left\{\begin{array}{c}
\lambda_{1} \\
\lambda_{2} \\
\cdot \\
\cdot \\
\cdot \\
\lambda_{n}
\end{array}\right\}, a=\left\{\begin{array}{c}
c \\
b_{2} \\
\cdot \\
\cdot \\
\cdot \\
b_{d}
\end{array}\right\}, b=\left\{\begin{array}{c}
b_{1} \\
b_{2} \\
\cdot \\
\cdot \\
\cdot \\
b_{d}
\end{array}\right\}, F=\left\{\begin{array}{c}
f\left(x_{1}\right) \\
f\left(x_{2}\right) \\
\cdot \\
\cdot \\
\cdot \\
f\left(x_{2}\right)
\end{array}\right\}
\end{gathered}
$$

where $\phi$ and $d$ are the $\mathrm{n} \times \mathrm{n}$ matrix and the dimension of vector $\mathbf{X}$, respectively.

In this study, the multi-quadratic models of the radius basic function are used to render the nonlinear approximations, which are presented using Eq. 19.

$$
\phi(\mathrm{r})=\sqrt{r^{2}+\gamma^{2}}
$$

Four evaluating criteria, including the $\mathrm{R}^{2}$ value, the root mean square error (RMSE), the max absolute error (MAE), and the average absolute error (AAE) are used to investigate the predictive accuracy of the RBF models.

R-squared $\left(\mathrm{R}^{2}\right)$ presents the coefficient of determination, between 0 and 1 where $\mathrm{R}^{2}=1$ means no error between the observed an approximated values. The $\mathrm{R}^{2}$ coefficient is defined as 
the ratio of explained variation to total variation. R-squared is a statistical measure of the degree of fit. The value of $\mathrm{R}^{2}$ is computed as follows:

$$
R^{2}=1-\frac{\sum_{i}\left(y_{i}-\hat{y}_{i}\right)^{2}}{\sum_{i}\left(y_{i}-\bar{y}_{i}\right)^{2}}
$$

where $\mathrm{n}, y_{i}, \bar{y}_{i}$ and $\hat{y}_{i}$ are the number of test points, the observed value, the mean of observed value, and the approximated value, respectively.

The root mean square error (RSME) is a quadratic scoring rule, which is used to measure the average magnitude of the error. In other words, it's the square root of the average of squared differences between prediction and actual observation. The value of RSME is calculated as follows:

$$
R M S E=\sqrt{\frac{\sum_{i=1}^{n}\left(y_{i}-\hat{y}_{i}\right)^{2}}{n}}
$$

The maximum absolute error (MAE) denotes the maximum difference between observed and approximated values. The value of MAE is computed as follows:

$$
M A E=\max \left|y_{i}-\$_{i}\right|
$$

The average absolute error (AAE) presents the average difference between observed and approximated values. The value of AAE is calculated as follows:

$$
A A E=\frac{\sum_{i=1}^{n}\left|y_{i}-\$_{i}\right|}{n}
$$

\section{Experimental setting and measurements}

Milling tests were performed in a Spinner U620 machining center (Fig. 3a). The dimensions of machining specimens were $350 \mathrm{~mm} \times 150 \mathrm{~mm} \times 25 \mathrm{~mm}$. The tool holder equipped with two inserts is $12 \mathrm{~mm}$ in diameters. The different wiper inserts having $0.2 \mathrm{~mm}, 0.4 \mathrm{~mm}$, and $0.8 \mathrm{~mm}$ of the nose radius are used in the milling trials. 
Power Meter KEW6305 was used to measure the power consumption during the milling process. Three clamp sensors were connected to the three-phase power lines of CNC machine with correct direction. The observed data was stored on a flashcard and analyzed with the aid of the KEW6305 software on the computer, as shown in Fig. 3b.

The surface roughness was measured using a tester Mitutoyo SJ-301 in the vertical and horizontal directions. The average values of the roughness properties were observed from five different points (Fig. 3c).

The representative values of the active power consumed at different inputs are depicted in Fig. 4. The profiles of the surface roughness are shown in Fig. 5. The variations of the power factor in the processing time are illustrated in Fig. 6.

\section{Results and discussion}

\subsection{Investigation of model accuracy}

The experimental results of the dry milling process are given in Table 2.

The values of the $\mathrm{R}^{2}$, RMSE, MAE, and AAE for three technical responses are listed in Table 3. The $\mathrm{R}^{2}$-values of the PF, EC, and $\mathrm{R}_{\mathrm{a}}$ are $0.9954,0.9921$, and 0.9938 , respectively, showing the perfect correlation between predicted values and observed values (Fig. 7). This $\mathrm{R}^{2}$ value is comparable with other established models, reported by ${ }^{35-37}$, warranting the acceptance of the present model. The small values of the evaluating errors (RMSE, MAE, and AAE) indicate the adequacy of the proposed models.

In this study, the experimental data from 1 to 25 are used to develop the RBF models. The experimental data from 26 to 29 are adopted to test the accuracy of the obtained models. The comparisons between experimental and predictive values at the random points are shown in Fig. 8. The small errors indicate that the RBF models are adequate and can be used for the optimizing process. 


\subsection{Parametric effects}

The effects of the inputs on the power factor shown in Fig. 9 pointed out that the higher levels of the processing inputs, including the cutting speed, depth of cut, feed rate, and nose radius lead to a higher power factor. Fig. 9a exhibits the impacts of the cutting speed and nose radius on the power factor. At a higher value of the cutting speed, the consumed power of the motor increases in order to reach the desired value of the spindle speed. Therefore, the active power increases, leading to a higher power factor. As nose radius increases, the cutting edge becomes curved, which results in more material deformation at the cutting area and thus higher energy consumption. Moreover, a larger radius increases the length of the cutting edge; hence, more power is consumed to overcome the frictional resistance. Therefore, a higher nose radius leads to an increased load on the motor; hence, the power factor improves.

The influences of the feed rate and depth of cut on the power factor are displayed in Fig. $9 b$. When the feed and depth of cut increases, the undeformed chip section increases. This results in higher machining forces ${ }^{38,39}$; hence the machine tool consumes more power. In fact, an increment in the depth of cut or feed rate causes an increased load on the motor to remove a higher material volume. As a result, higher active power is observed, resulting in an increment in the power factor.

Fig. 9c shows that $\mathrm{f}$ is the most effective parameter on the power factor due to the highest contribution regarding single term $(22.81 \%)$, followed by a $(16.33 \%), \mathrm{V}(14.98 \%)$, and $\mathrm{r}$ (10.64\%), respectively. When the feed rate increases, the cutting forces and the cutting momentum also increase. Hence, the active power of the servo spindle motor and the feed drive motors increases. As a result, the PF rises up. The feed rate has more effect on the PF than that of cutting speed due to the contribution of the active power of the feed drive motors. When the feed rate increases, the reaction forces on the $\mathrm{X}$ and $\mathrm{Y}$-axis of the feed drive system as well as the cutting momentum on the spindle motor increase. Therefore, the total active power of 
movement system increase. The significant quadratic terms have significant impacts, in which $\mathrm{r}^{2}$ has the largest contribution (8.42\%); followed by $\mathrm{f}^{2}(6.31 \%), \mathrm{V}^{2}(5.77 \%)$ and $\mathrm{a}^{2}(2.68 \%)$, respectively.

The interaction impacts of the processing conditions on energy consumption are shown in Fig. 10. Fig. 10a depicts the impacts of the cutting speed and depth of cut on energy consumption. An increment in the depth of cut increases the undeformed chip section and the degree of plastic deformation ${ }^{40}$. The greater resistance in the chip formation increases and higher energy is consumed. As the cutting speed increases, energy consumption significantly decreases. An increased cutting speed causes an increment in the temperature of the cutting region; hence, the hardness and strength of the workpiece are decreased. The softened part of material causes lower machining forces, as compared to its harder state. Additionally, an increased cutting speed leads to a decrease in the frictional coefficient and the lower cutting force is obtained. Therefore, higher cutting speed generates low cutting forces which result in less energy consumption. In contrast, it is obvious that the material removal rate would be higher when the cutting speed increased. The process parameters, including the cutting speed, feed, and depth of cut determine the material removal rate. An increment in the material removal rate requires higher power consumption. Higher rate of material removal required a higher power to turn the spindle motor.

The impacts of the feed rate and nose radius on energy consumption are shown in Fig. 10b. Higher feed rate causes a rise in heat generated on the workpiece surface and tool and may lead to the formation of build-up-edge (BUE). The BUE can increase the cutting forces due to an increment in the contact area between the cutting tool and workpiece, resulting in higher power consumed. Additionally, the BUE causes an increase in the cutting tool temperature, which leads to an increase in the mechanical strength of the chip due to the work-hardening behavior. Obviously, higher power consumed is required to detach material. Fortunately, a higher value of 
the feed rate or cutting speed leads to a decrease in the cutting time, resulting in a reduction in the energy consumed. Reduction in energy consumption with an increase in feed rate and/or cutting speed is logical because it results in faster machining and less processing time ${ }^{41}$. It is inferred from Fig. 10b that an increased radius leads to an increment in cutting edge; hence, the cutting tool becomes blunt. The degree of the material deformation increases and more energy is required to overcome the resistance friction ${ }^{42}$.

In Fig. 10c, it is found that $\mathrm{f}$ is the most effective parameter on energy consumption due to the highest contribution regarding single term (29.78\%), followed by V (19.55\%), a (5.00\%), and $\mathrm{r}(2.92 \%)$, respectively. It is observed that energy consumption for the milling process is highly sensitive to feed rate as compared to the cutting speed due to the greater impact of the feed drive motors. As the feed rate increases, the load of the motor on the feed drive systems increases to reach the desired value and higher reaction forces are required. Therefore, the power used of movement system increases. The term $\mathrm{f}^{2}$ has the largest contribution with respect to the quadratic terms $(15.46 \%)$, followed by $\mathrm{V}^{2}(9.07 \%), \mathrm{r}^{2}(1.11 \%)$ and $\mathrm{a}^{2}(0.43 \%)$, respectively.

Fig. 11 depicted the influences of machining parameters on the surface roughness. The influences of the cutting speed and nose radius on the surface roughness are shown in Fig. 11a. An increment in the cutting speed leads to a decrease in the strength and hardness of the workpiece due to an increase in the temperature of the cutting region. The chip produced is easily detached from the workpiece, resulting in a reduction in surface roughness. Additionally, higher cutting speed reduces cutting forces together with the effect of natural frequency and vibration, giving a better surface finish. Moreover, the possibility of the formation of the BUE at high cutting speed is comparatively lower and thus generates smoother surfaces. An increased radius results in an increment in contact length between the milled surface and tool radius, leading to smaller peaks on the trail. The roughness profile is decreased with a high tip radius, 
resulting in a smoother surface. Additionally, the chatter could be suppressed due to an increment in stand damping with an increased radius ${ }^{43}$.

Fig. $11 \mathrm{~b}$ shows that an increased roughness is associated with the increased feed rate and/or depth of cut. At a low value of the feed rate, the distance between the peak and crest of the machined surface is short; hence, a smoother surface is produced. An increase in the feed rate causes higher distance between the peaks generated by the tool grooves left on the milled surface. Therefore, roughness values increase with feed rate due to more feed marks on the machined surface. At a higher value of the feed rate, the BUE can result in grooves formation and increases the degree of the plastic deformation. The machining parts of the workpiece are heavily detached from the surface, leading to a worsening surface ${ }^{44}$. As the depth of cut increases, the contact area between the workpiece and the cutting tool increases, resulting in an increment in the material removal volume and cutting forces. It is also possible that the increment in the cutting forces, due to the increase of depth of cut above the stability lobe, caused chatter in machine tool which eventually resulted in poor surface finish i.e. an increase in surface roughness ${ }^{45}$. Low depth of cut should be used to decrease the tendency of chatter.

Fig. 11c shows the effects of machining parameters on the surface roughness. As a result, the percentage contributions of the $\mathrm{f}, \mathrm{r}$, a, and $\mathrm{V}$ are $17.37 \%, 16.26 \%, 16.11 \%$, and $13.91 \%$, respectively. All quadratic factors have significant effects, in which $\mathrm{f}^{2}$ is the most influenced factor (14.36\%), followed by $\mathrm{V}^{2}(3.69 \%), \mathrm{r}^{2}(2.79 \%)$ and $\mathrm{a}^{2}(2.54 \%)$, respectively.

The effects of different processing factors on the machined surface morphology are exhibited in Fig. 12. The machined defects such as pits, voids, and grooves are appeared at low cutting speed, as depicted in Fig. 12a. The smooth cut and small waviness, as well as grooves, are observed at a higher value of the cutting speed (Fig. 12b). The surface faults, including cracks, grooves, and valleys are displayed at the highest feed rate (Fig. 12d), as compared to the lowest one (Fig. 12c). 
The wear behaviors of the inserts at various machining conditions are shown in Fig. 13. As depicted in Fig. 13a, the wear pattern is not much prominent, no groove or skin depletion. However, when the feed rate was increased, the wear pattern shows crater wear on the rake face, associated with edge chipped off - the fracture of cutting edge. To support this, it can be seen from Table 2, the power factor is increased from 0.566 to 0.752 (32\% increase), and the resulted surface roughness increased from 0.98 to 1.55 (58\% increase). An increased input leads to a higher temperature at the nose region, which causes excessive pressure and stress. The deformation of the cutting edge is increased with an increment in the factor, leading to the reduction of the hardness of the tool.

\subsection{Optimal results}

The pre-processing and corresponding values for two objectives after a linear normalization are listed in Table 4. The values of the GRC are shown in Table 5. As depicted in Table 6 , the percentage contribution of the first principal component is $52.00 \%$, followed by the second component (33.20\%) and the third one (14.70\%), respectively. The weight values are calculated based on the squares of subsequent eigenvectors of the three principal components. Table 7 revealed that the weight values of the power factor (PF), energy consumption (EC), and surface roughness $\left(\mathrm{R}_{\mathrm{a}}\right)$ using the principal component analysis (PCA) method are $0.32,0.35$, and 0.33 , respectively.

The mathematical formulas showing the relationship between inputs and outputs are used to find optimal parameters with the support of the DA. A total of 29 optimal results are observed and the point with the $\mathrm{D}$ values close to 1 is the best solution. The optimal values of the inputs are shown in Fig. 14a. The values of the desirability are depicted in Fig. 14b. The desirability of 0.97515 revealed that the optimal results observed are reliable and feasible. As revealed in Table 8, the reduction of the EC and $\mathrm{R}_{\mathrm{a}}$ are about $34.85 \%$ and $57.65 \%$, respectively, while the PF increases around $28.83 \%$, as compared to the initial values. 
To evaluate the effectiveness of the proposed approach, a confirmatory experiment is conducted at the optimal solution. The experimental results are exhibited in Fig. 15. The comparative results are shown in Table 9. The small errors (below $5 \%$ ) indicate that optimal results are strongly correlated with the experimental data. The similar ranges for the predictive errors can be found in the works of 46,47 . Therefore, the developed approach can be effectively applied to the optimization of different milling processes.

As mentioned in the previous section, wet machining with liquid coolants is normally used in metal-machining operations and processes to reduce the temperature of both workpiece and tool and to evacuate chips from the cutting area. However, the heavy use of coolant fluids is not cost-effective and causes poor environmental impacts, especially there are more and more concerns regarding safety and environmental legislations applied in manufacturing industries, with emerging trends towards sustainable manufacturing. Today, dry machining is considered as one of the eco-friendly machining processes, with good environmental impacts and costeffectiveness. Dry machining is becoming more prevalent, and it also helps to increase tool life when machining the steels, cast iron, and some stainless materials. There have been emerging needs and growing efforts to investigate optimal machining process parameters for the dry machining operations. This study focuses on the optimization of the machining process parameters, aimed to enhance simultaneously the power factor, energy consumption, and surface roughness. A study did take into account not only the technical issues related to the machining process quality (surface roughness) but also environmental impacts and sustainable manufacturing ones: maximizing the power factor and decreasing the energy consumption. A specific case study of dry machining of stainless steel 304 was successfully implemented to investigate optimizations of the machining process parameters and cutting tool's geometry for simultaneous improvements of the power factor (PF), energy consumption (EC), and surface roughness $(\mathrm{Ra})$. The outcomes and findings of the investigated work in this study can be used for 
further research in sustainable design and manufacturing as well as directly used in the knowledge-based and expert systems for dry milling applications in industrial practices.

\section{Conclusions}

This paper presents a multi-response optimization which aims to simultaneously enhance the power factor $(\mathrm{PF})$, decrease the energy consumption (EC), and improve the machining quality via reduction of the surface roughness $\left(\mathrm{R}_{\mathrm{a}}\right)$, for the specific case of dry machining of stainless steel 304. The radial basis function (RBF) models of three technical responses were developed in terms of the machining process parameters, including the cutting velocity $(V)$, feed rate $(f)$, depth of cut $(a)$, and tool nose radius $(r)$. An integrative approach, including the grey relation analysis (GRA), the principal component analysis (PCA), and desirability approach (DA) was used to calculate the weight objectives and predict the optimal values of machining process parameters (cutting velocity, feed rate, depth of cut, and tool nose radius). The key conclusions of this study can be presented as follows:

1. The RBF models for the power factor (PF), energy consumption (EC), and surface roughness $\left(R_{a}\right)$, have $R^{2}$-values of $0.9954,0.9921$, and 0.9938 , respectively. This indicates a good agreement between the predicted and experimental values. The proposed optimization models adequately exhibit the nonlinear relationships among process parameters and machining responses or technical outputs (power factor, energy consumption, and surface roughness). The developed correlations can be used to predict the optimal machining process parameters with a sufficient accuracy when dry-machining of stainless steel 304.

2. It can be concluded that the processing conditions, including the cutting speed $(V)$, depth of cut $(a)$, feed rate $(f)$, and tool nose radius $(r)$, have significant impacts on the technical outputs, including power factor $(\mathrm{PF})$, energy consumption $(\mathrm{EC})$, and surface roughness $\left(\mathrm{R}_{\mathrm{a}}\right)$. In order to increase the power factor, the maximal levels of the process parameters are recommended for utilization. The highest values of the cutting speed and feed rate can be used to save the energy 
consumption, while the lowest levels of the depth of cut and nose radius cause a decrease in consumed energy. The low values of the depth of cut and feed rate are recommended to decrease the surface roughness. The highest levels of the tool nose radius and cutting speed can be used to get a smoother surface.

3. The selection of the weight of objectives could give a better solution to determine the optimal machining process parameters. The optimal values of cutting speed $(V)$, depth of cut $(a)$, feed rate $(f)$, and tool nose radius $(r)$, are $160 \mathrm{~m} / \mathrm{min}, 0.42 \mathrm{~mm}, 0.09 \mathrm{~mm} / \mathrm{z}$, and $0.8 \mathrm{~mm}$, respectively. The power factor improves about $28.83 \%$, and the energy consumption and surface roughness decrease approximately $34.85 \%$ and $57.65 \%$ at the optimal solution using the weight values generated by Principal Component Analysis (PCA).

4. The hybrid approach including the RBF (Radial Basis Function) models, GRA (Grey Relation Analysis), PCA (Principal Component Analysis), and DA (Desirability approach) can facilitate the optimization of the milling process; and this approach gives a reliable optimal solution, as compared to using practical experience or operation guide.

5. Practically, the variation of the inputs (process parameters: cutting speed, depth of cut, feed rate, and tool nose radius) may lead to a conflict or contradictory impacts on the outputs (power factor, energy consumption and surface roughness) in dry-milling. In this way, a comprehensive optimization should be considered with more objectives, such as surface properties, tool life, and machining productivity.

\section{ACKNOWLEDGMENT}

This research is funded by Vietnam National Foundation for Science and Technology Development (NAFOSTED) under grant number 107.04-2017.06

This work was also supported by a Researcher Links workshop grant, 2017-RLWK9-11081, under the Newton Fund Vietnam Programme partnership. The grant is funded by the UK 
Department of Business, Energy and Industrial Strategy (BEIS) and delivered by the British Council. For further information, please visit www.newtonfund.ac.uk.

\section{DECLARATION OF CONFLICTING INTERESTS}

The author(s) declared no potential conflicts of interest with respect to the research, authorship, and/or publication of this article.

\section{REFERENCES}

1. Krolczyk GM, Maruda RW, Krolczyk JB, et al. Ecological trends in machining as a key factor in sustainable production - A review. Journal of Cleaner Production 2019; 218: 601-615. DOI: https://doi.org/10.1016/j.jclepro.2019.02.017.

2. Gupta S, Dangayach G, Singh AK, et al. A pilot study of sustainable machining process design in Indian process industry. CAD/CAM, Robotics and Factories of the Future. Springer, 2016, pp.379-385.

3. Bagaber SA and Yusoff AR. Multi-objective optimization of cutting parameters to minimize power consumption in dry turning of stainless steel 316. Journal of Cleaner Production 2017; 157: 30-46.

4. Danish M, Ginta TL, Habib K, et al. Thermal analysis during turning of AZ31 magnesium alloy under dry and cryogenic conditions. The International Journal of Advanced Manufacturing Technology 2017; 91: 2855-2868.

5. Mia M and Dhar NR. Modeling of Surface Roughness Using RSM, FL and SA in Dry Hard Turning. Arabian Journal for Science and Engineering 2018; 43: 1125-1136. DOI: $10.1007 / \mathrm{s} 13369-017-2754-1$.

6. Bhopale NN, Pawade RS and Joshi SS. Surface quality analysis in ball end milling of Inconel 718 cantilevers by response surface methodology. Proceedings of the Institution of Mechanical Engineers, Part B: Journal of Engineering Manufacture 2017; 231: 628-640. 
7. Chen H-Q and Wang Q-H. Modelling and simulation of surface topography machined by peripheral milling considering tool radial runout and axial drift. Proceedings of the Institution of Mechanical Engineers, Part B: Journal of Engineering Manufacture 2019: 0954405419838384.

8. Babu GP, Murthy B, Venkatarao K, et al. Multi-response optimization in orthogonal turn milling by analyzing tool vibration and surface roughness using response surface methodology. Proceedings of the Institution of Mechanical Engineers, Part B: Journal of Engineering Manufacture 2017; 231: 2084-2093.

9. Le Coz G and Dudzinski D. Temperature variation in the workpiece and in the cutting tool when dry milling Inconel 718. The International Journal of Advanced Manufacturing Technology 2014; 74: 1133-1139.

10. Jomaa W, Lévesque $\mathrm{J}$, Bocher $\mathrm{P}$, et al. Optimization study of dry peripheral milling process for improving aeronautical part integrity using Grey relational analysis. The International Journal of Advanced Manufacturing Technology 2017; 91: 931-942.

11. Khettabi R, Nouioua M, Djebara A, et al. Effect of MQL and dry processes on the particle emission and part quality during milling of aluminum alloys. The International Journal of Advanced Manufacturing Technology 2017; 92: 2593-2598.

12. Safari H, Sharif S, Izman S, et al. Surface integrity characterization in high-speed dry end milling of Ti-6Al-4V titanium alloy. The International Journal of Advanced Manufacturing Technology 2015; 78: 651-657.

13. Shihab SK, Khan ZA, Mohammad A, et al. Optimization of surface integrity in dry hard turning using RSM. Sadhana 2014; 39: 1035-1053.

14. Angappan P, Thangiah S and Subbarayan S. Taguchi-based grey relational analysis for modeling and optimizing machining parameters through dry turning of Incoloy $800 \mathrm{H}$. Journal of Mechanical Science and Technology 2017; 31: 4159-4165. 
15. Krolczyk G, Nieslony P and Legutko S. Determination of tool life and research wear during duplex stainless steel turning. Archives of Civil and Mechanical Engineering 2015; 15: 347-354.

16. Baowan $\mathrm{P}$, Saikaew $\mathrm{C}$ and Wisitsoraat A. Influence of helix angle on tool performances of TiAlN-and DLC-coated carbide end mills for dry side milling of stainless steel. The International Journal of Advanced Manufacturing Technology 2017; 90: 3085-3097.

17. Pham T-H, Nguyen D-T, Banh T-L, et al. Experimental study on the chip morphology, tool-chip contact length, workpiece vibration, and surface roughness during high-speed face milling of A6061 aluminum alloy. Proceedings of the Institution of Mechanical Engineers, Part B: Journal of Engineering Manufacture 2019: 0954405419863221.

18. Jahan MP, Ma J, Hanson C, et al. Tool wear and resulting surface finish during micro slot milling of polycarbonates using uncoated and coated carbide tools. Proceedings of the Institution of Mechanical Engineers, Part B: Journal of Engineering Manufacture 2019: 0954405419862479.

19. Mia M and Dhar NR. Influence of single and dual cryogenic jets on machinability characteristics in turning of Ti-6Al-4V. Proceedings of the Institution of Mechanical Engineers, Part B: Journal of Engineering Manufacture 2019; 233: 711-726. DOI: $10.1177 / 0954405417737581$.

20. Kant G and Sangwan KS. Prediction and optimization of machining parameters for minimizing power consumption and surface roughness in machining. Journal of Cleaner Production 2014; 83: 151-164. DOI: https://doi.org/10.1016/j.jclepro.2014.07.073.

21. Mia M, Królczyk G, Maruda R, et al. Intelligent Optimization of Hard-Turning Parameters Using Evolutionary Algorithms for Smart Manufacturing. Materials 2019; 12: 879. 
22. Zhang C, Zhou Z, Tian G, et al. Energy consumption modeling and prediction of the milling process: a multistage perspective. Proceedings of the Institution of Mechanical Engineers, Part B: Journal of Engineering Manufacture 2018; 232: 1973-1985.

23. Nur R, Noordin M, Izman S, et al. Machining parameters effect in dry turning of AISI 316L stainless steel using coated carbide tools. Proceedings of the Institution of Mechanical Engineers, Part E: Journal of Process Mechanical Engineering 2017; 231: 676-683.

24. Bagaber SA and Yusoff AR. Energy and cost integration for multi-objective optimisation in a sustainable turning process. Measurement 2019; 136: 795-810.

25. Zhang H, Deng Z, Fu Y, et al. A process parameters optimization method of multi-pass dry milling for high efficiency, low energy and low carbon emissions. Journal of Cleaner Production 2017; 148: 174-184.

26. Song Q, Liu Z, Ju G, et al. A generalized cutting force model for five-axis milling processes. Proceedings of the Institution of Mechanical Engineers, Part B: Journal of Engineering Manufacture 2019; 233: 3-17.

27. Kuram E. Micro-milling of unreinforced and reinforced polypropylene. Proceedings of the Institution of Mechanical Engineers, Part B: Journal of Engineering Manufacture 2019; 233: 87-98.

28. Yang $\mathrm{S}, \mathrm{He} \mathrm{C}$ and Zheng $\mathrm{M}$. Investigation on the stress field of milling titanium alloys with micro-textured ball-end milling cutter. Proceedings of the Institution of Mechanical Engineers, Part B: Journal of Engineering Manufacture 2019: 0954405419831491.

29. Khorram A. Laser brazing of 321 and 410 stainless steels with AMS 4777 filler metal: Experimental and numerical study. Proceedings of the Institution of Mechanical Engineers, Part B: Journal of Engineering Manufacture 2019; 233: 1062-1074.

30. Balaji M, Murthy B and Rao NM. Multi response optimization of cutting parameters in drilling of AISI 304 stainless steels using response surface methodology. Proceedings of the 
Institution of Mechanical Engineers, Part B: Journal of Engineering Manufacture 2018; 232: 151-161.

31. Prieto J, Jones M, Barrero F, et al. Comparative analysis of discontinuous and continuous PWM techniques in VSI-fed five-phase induction motor. IEEE Transactions on Industrial Electronics 2011; 58: 5324-5335.

32. Basak S, Prasad KS, Mehto A, et al. Parameter optimization and texture evolution in single point incremental sheet forming process. Proceedings of the Institution of Mechanical Engineers, Part B: Journal of Engineering Manufacture 2019: 0954405419846001.

33. Lal S, Kumar S, Khan ZA, et al. Multi-response optimization of wire electrical discharge machining process parameters for A17075/A12O3/SiC hybrid composite using Taguchi-based grey relational analysis. Proceedings of the Institution of Mechanical Engineers, Part B: Journal of Engineering Manufacture 2015; 229: 229-237.

34. Hussain MF, Barton RR and Joshi SB. Metamodeling: radial basis functions, versus polynomials. European Journal of Operational Research 2002; 138: 142-154.

35. Mia M and Dhar NR. Prediction of surface roughness in hard turning under high pressure coolant using Artificial Neural Network. Measurement 2016; 92: 464-474.

36. Muthukrishnan N and Davim JP. Optimization of machining parameters of A1/SiC-MMC with ANOVA and ANN analysis. Journal of Materials Processing Technology 2009; 209: 225232.

37. Basheer AC, Dabade UA, Joshi SS, et al. Modeling of surface roughness in precision machining of metal matrix composites using ANN. Journal of Materials Processing Technology 2008; 197: 439-444.

38. Rahman MA, Rahman M and Kumar AS. Material perspective on the evolution of microand nano-scale cutting of metal alloys. Journal of Micromanufacturing 2018; 1: 97-114. 
39. Rahman MA, Rahman $\mathrm{M}$ and Kumar AS. Chip perforation and 'burnishinglike'finishing of Al alloy in precision machining. Precision Engineering 2017; 50: 393-409.

40. Rahman MA, Rahman M, Kumar AS, et al. CNC microturning: an application to miniaturization. International Journal of Machine Tools and Manufacture 2005; 45: 631-639.

41. Bagaber SA and Yusoff AR. Multi-responses optimization in dry turning of a stainless steel as a key factor in minimum energy. The International Journal of Advanced Manufacturing Technology 2018; 96: 1109-1122.

42. Park H-S, Nguyen T-T and Dang X-P. Multi-objective optimization of turning process of hardened material for energy efficiency. International journal of precision engineering and manufacturing 2016; 17: 1623-1631.

43. Singh D and Venkateswara Rao P. Optimization of tool geometry and cutting parameters for hard turning. Materials and Manufacturing Processes 2007; 22: 15-21.

44. Suresh Kumar Reddy N and Venkateswara Rao P. Performance improvement of end milling using graphite as a solid lubricant. Materials and Manufacturing Processes 2005; 20: $673-686$.

45. Altintas $\mathrm{Y}$ and Weck M. Chatter stability of metal cutting and grinding. CIRP annals 2004; 53: 619-642.

46. Nguyen T-T. Prediction and optimization of machining energy, surface roughness, and production rate in SKD61 milling. Measurement 2019; 136: 525-544.

47. Kumar R, Hynes NRJ, Pruncu CI, et al. Multi-objective optimization of green technology thermal drilling process using grey-fuzzy logic method. Journal of Cleaner Production 2019; 236: 117711. 


\section{Notation}

r Nose radius

AAE Average absolute error

BBM Box-Behnken method

BUE Build-up-edge

CNC Computer Numerical Control

DA Desirability approach

DM Dry machining

EC Energy consumption

GRA Grey relational analysis

GRC Grey relation coefficient

MAE Max absolute error

PCA Principal component analysis

PF Power factor

$\mathrm{R}_{\mathrm{a}} \quad$ Surface roughness

RBF Radial basis function

RMSE Root mean square error

RSM Response surface methodology

SEM Scanning electron microscopy

V Cutting speed 


\section{List of Figures}

Figure 1. The profile of power consumption with respect to time indicating different cutting stages

Figure 2. Systematic diagram showing the optimizing procedure

Figure 3. Experiments and measurements: (a) Dry milling experiments (b) Power measurements (c) Measuring surface roughness

Figure 4. The power consumption at various machining conditions:

(a) Experiment no. 1 (Replication-2), (b) Experiment no. 2 (Replication-2),

(c) Experiment no. 9 (Replication-3), (d) Experiment no. 13 (Replication-3)

Figure 5. Surface roughness at various machining conditions:

(a) Experiment no. 1 (Replication-2), (b) Experiment no. 11 (Replication-3),

(c) Experiment no. 16 (Replication-4), (d) Experiment no. 21 (Replication-3)

Figure 6 . The variations of the power factor at various machining conditions:

(a) Experiment no. 11 (Replication-3), (b) Experiment no. 20 (Replication-3),

(c) Experiment no. 24 (Replication-2)

Figure 7. Investigation of adequacy of RBF models: (a) Power factor, (b) Energy consumption, (c) Surface roughness

Figure 8. Validation of the accuracy for RBF models: (a) PF model, (b) EC model, (c) SR model Figure 9. The effects of machining parameters on the PF model: (a) PF versus V and r, (b) PF versus a and f, (c) Parameter contributions for the PF model

Figure 10. The effects of machining parameters on the EC model: (a) EC versus V and a,

(b) EC versus $r$ and f, (c) Parameter contributions for the EC model

Figure 11. Interaction effects of machining parameters on the $R_{a}$ model: (a) $R_{a}$ versus $r$ and $V$,

(b) $R_{a}$ versus f and a, (c) Parameter contributions on the $R_{a}$ model

Figure 12. SEM of surface morphology at various conditions: (a) Experiment no. 4,

(b) Experiment no.12, (c) Experiment no.1, (d) Experiment no. 7 
Figure 13. SEM images of the worn tool's rake surface at various machining conditions: (a) Experiment no. 16, (b) Experiment no. 20

Figure 14. Optimization results generated by DA: (a) Optimal values, (b) Bar graph of the desirability

Figure 15. Experimental results at the optimal solution: (a) Power consumed, (b) Power factor, (c) Surface roughness 


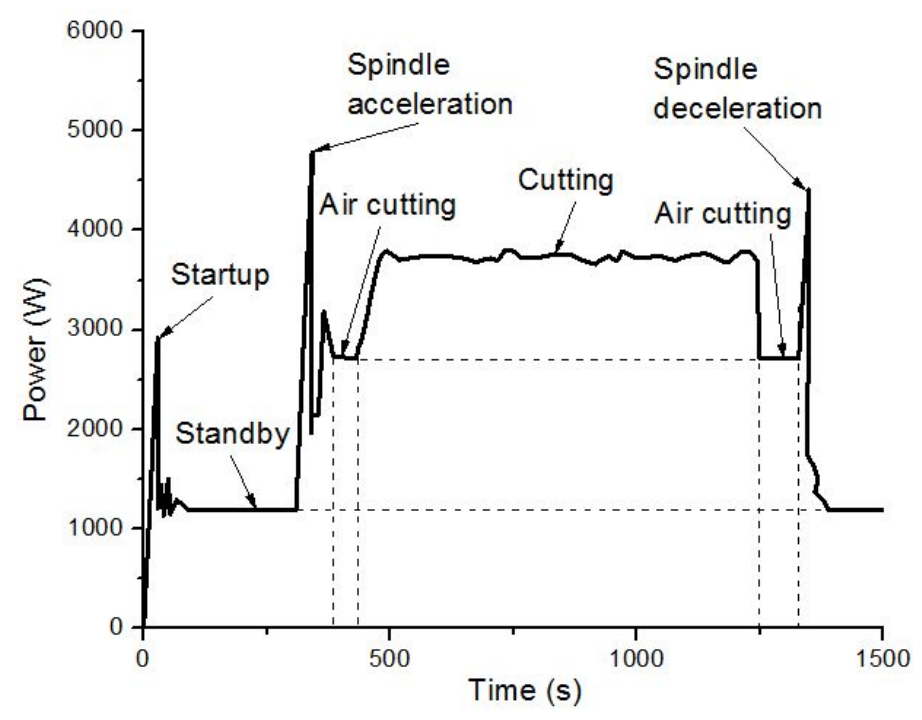

Figure 1. The profile of power consumption with respect to time indicating different cutting stages

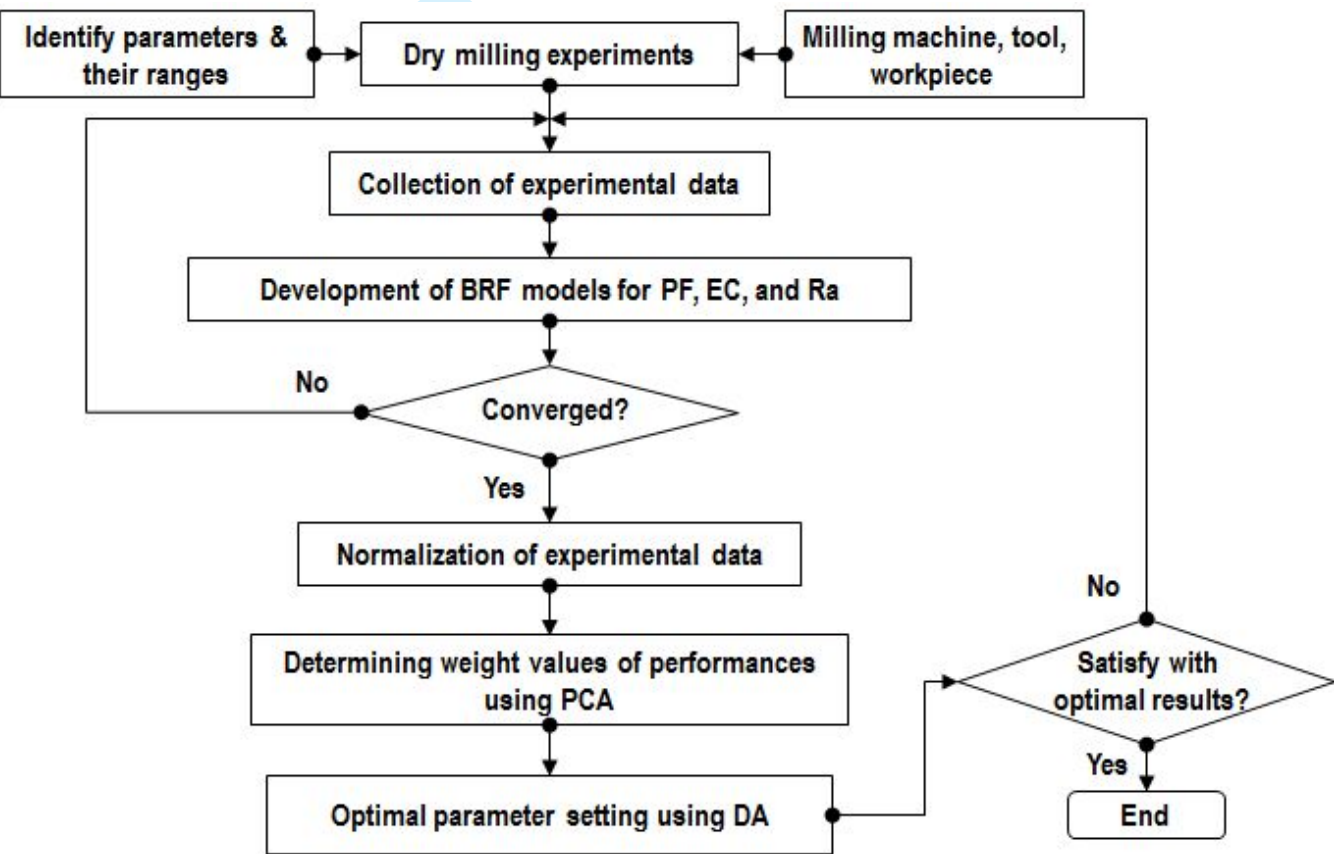

Figure 2. Systematic diagram showing the optimizing procedure 
a.

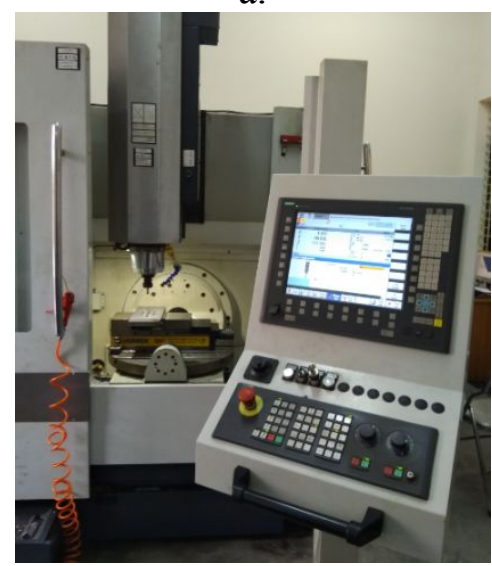

Figure 3. Experiments and measurements: (a) Dry milling experiments,

(b) Power measurements, (c) Measuring surface roughness
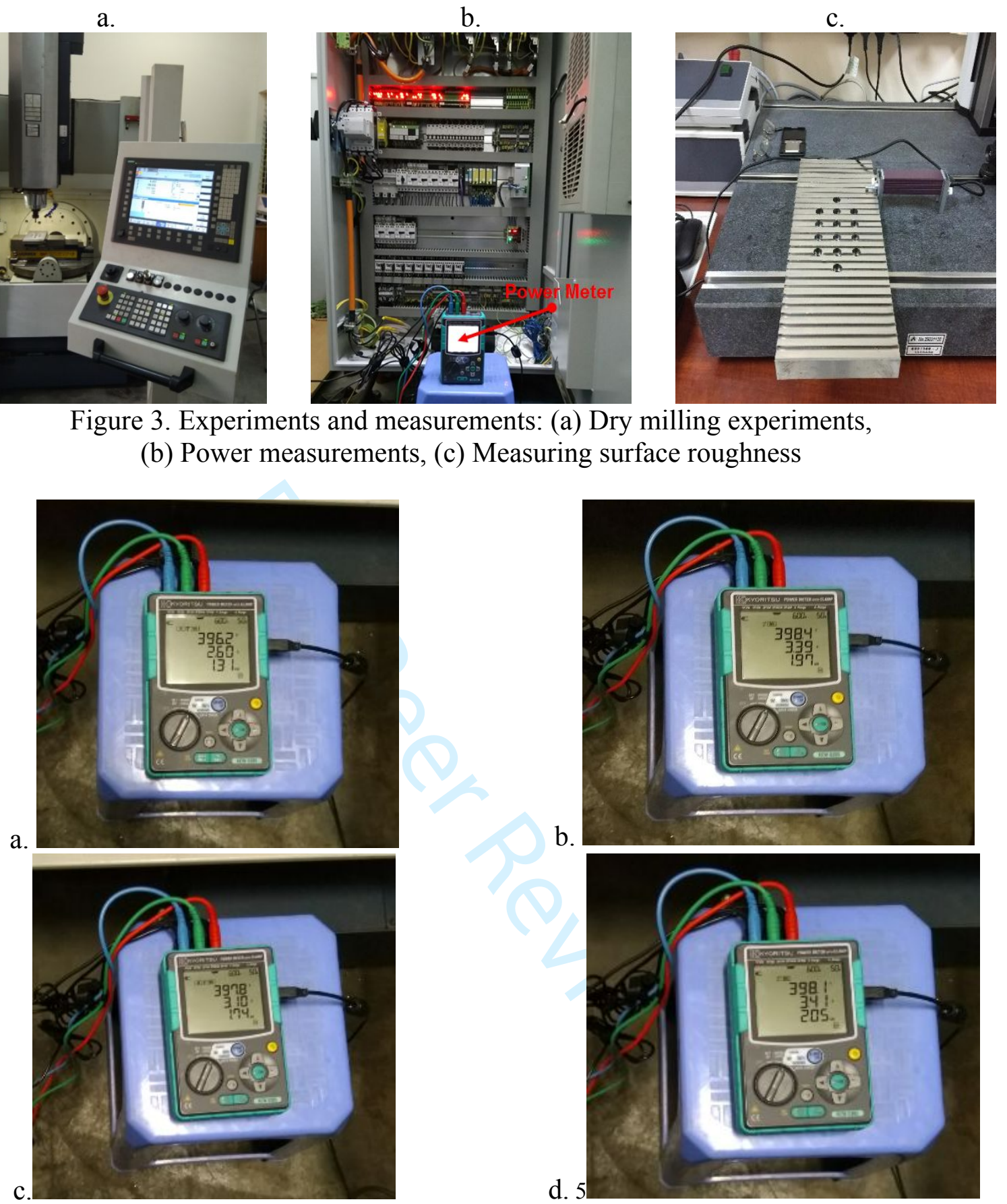

Figure 4. The power consumption at various machining conditions:

(a) Experiment no. 1 (Replication-2), (b) Experiment no. 2 (Replication-2),

(c) Experiment no. 9 (Replication-3), (d) Experiment no. 13 (Replication-3) 
a.
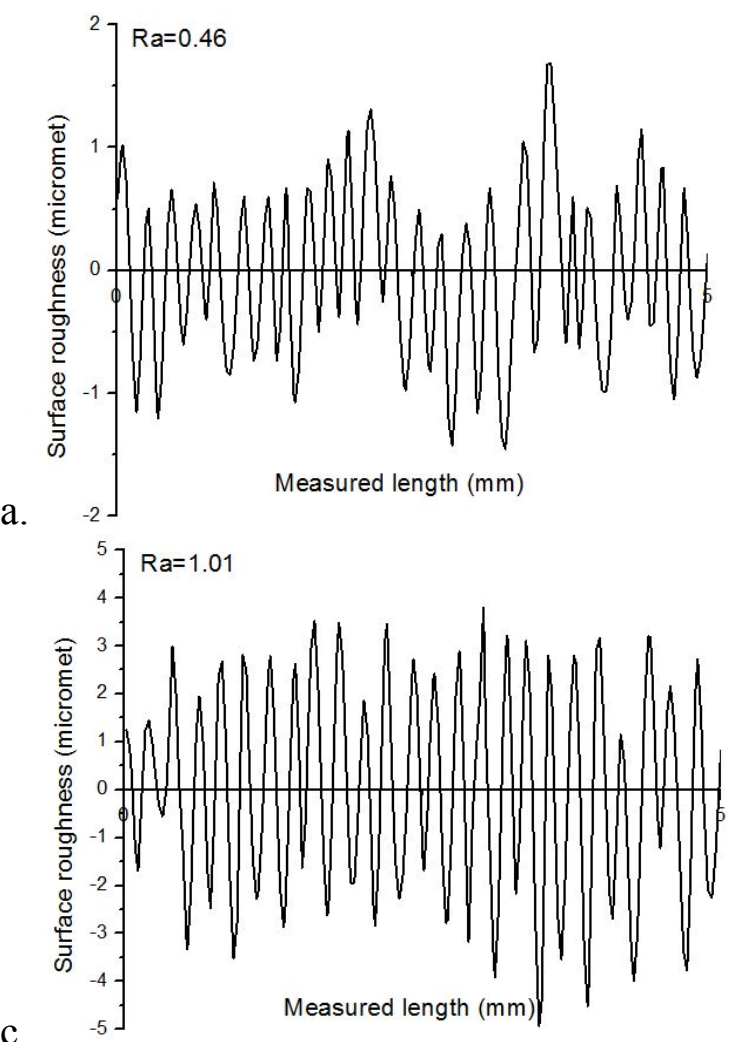

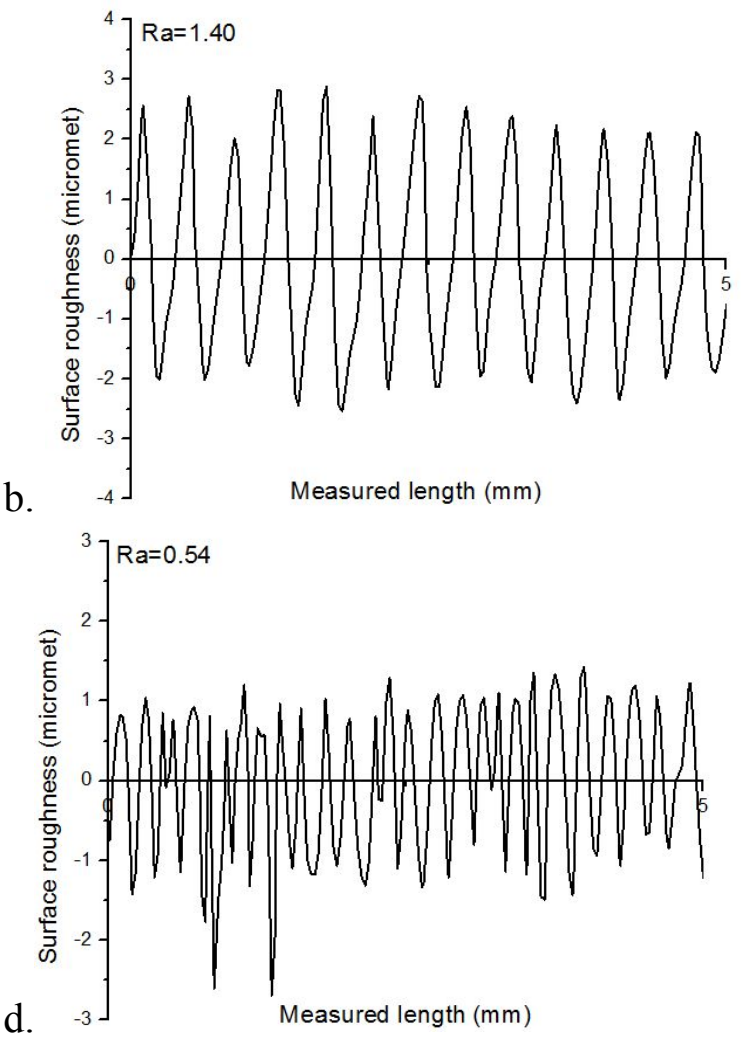

Figure 5. Surface roughness at various machining conditions:

(a) Experiment no. 1 (Replication-2), (b) Experiment no. 11 (Replication-3),

(c) Experiment no. 16 (Replication-4), (d) Experiment no. 21 (Replication-3) 
a.
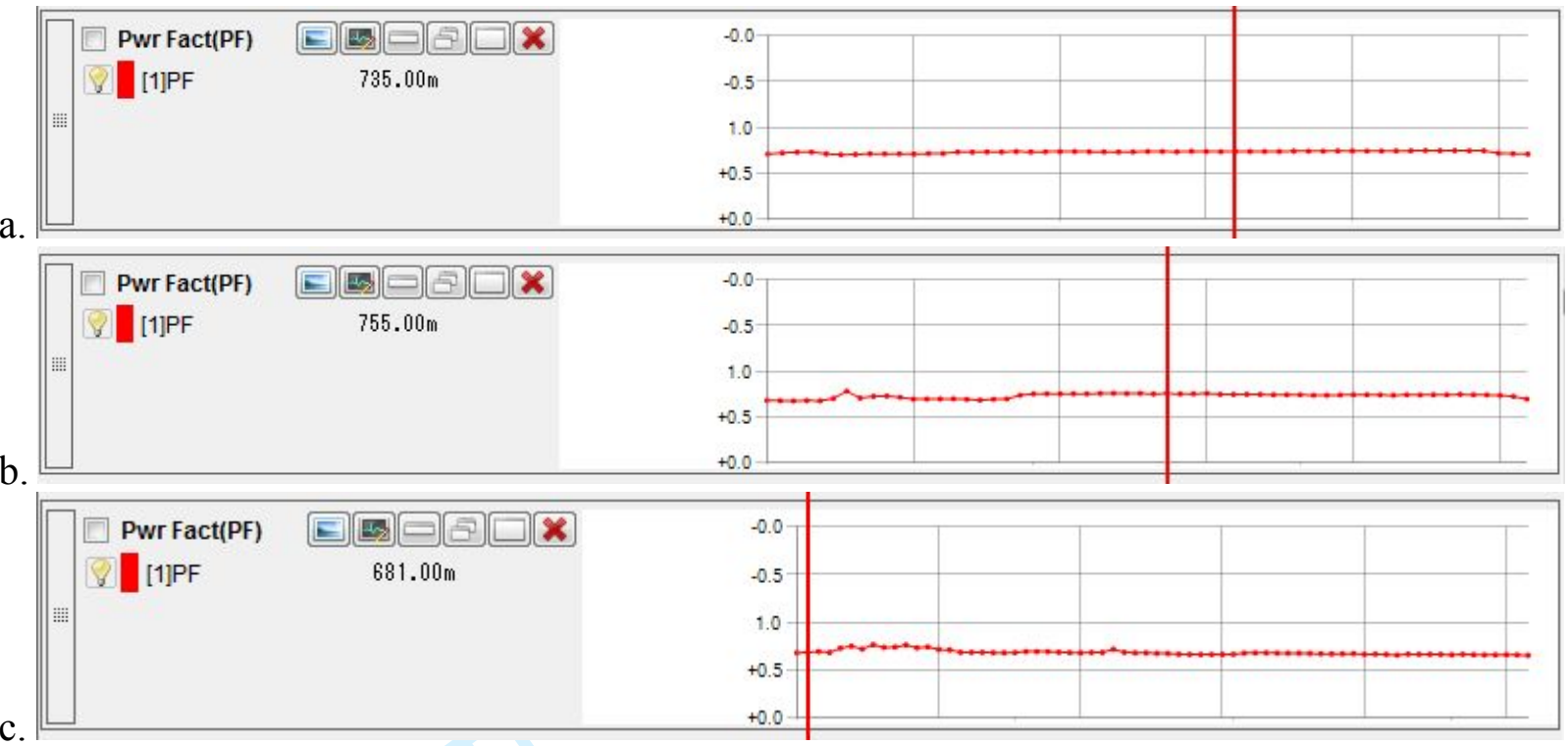

c.

Figure 6. The variations of the power factor at various machining conditions:

(a) Experiment no. 11 (Replication-3), (b) Experiment no. 20 (Replication-3), (c) Experiment no. 24 (Replication-2) 
a.

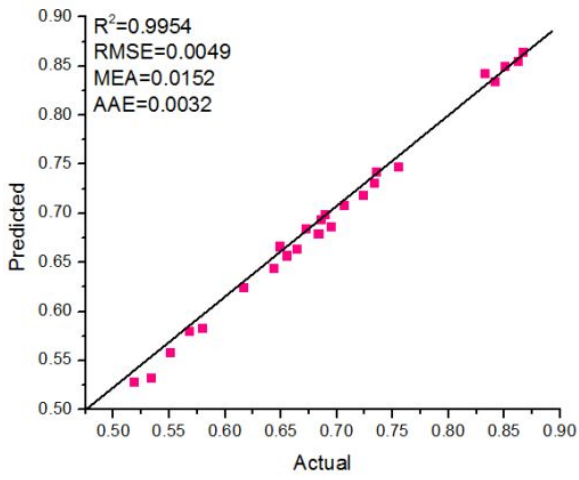

b.

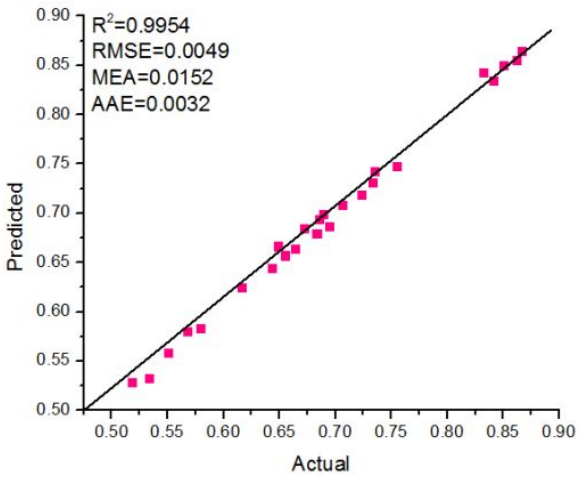

c.

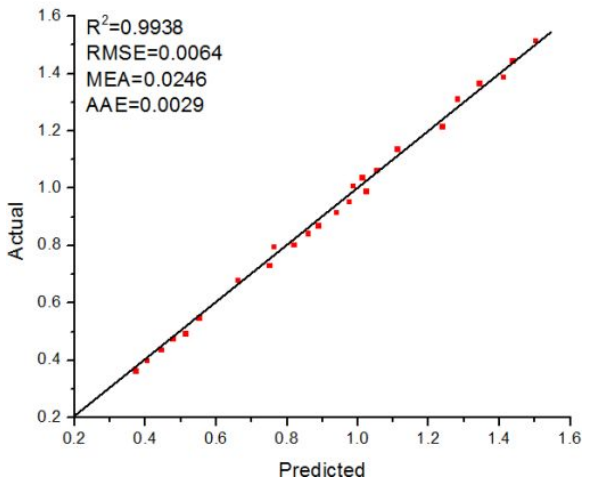

Figure 7. Investigation of adequacy of RBF models: (a) Power factor, (b) Energy consumption, (c) Surface roughness

a.

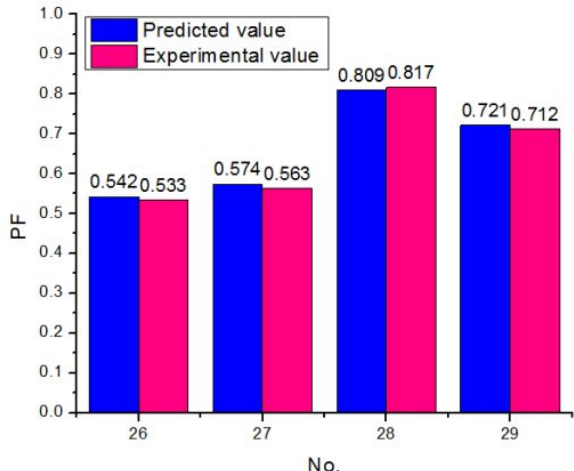

b.

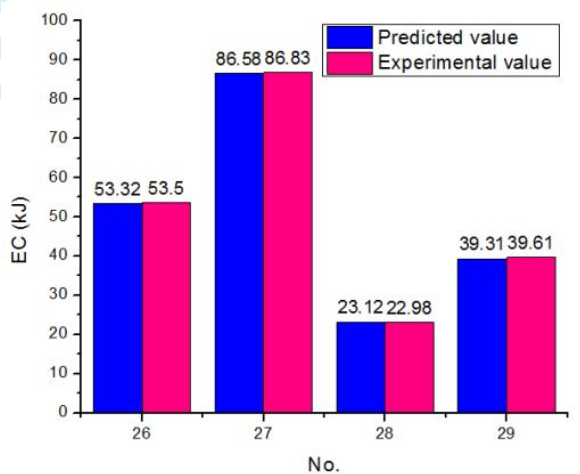

c.

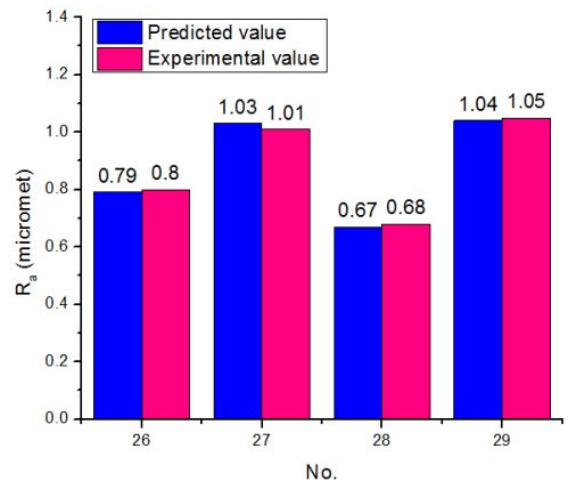

Figure 8. Validation of the accuracy for RBF models: (a) PF model, (b) EC model, (c) SR model 
a.
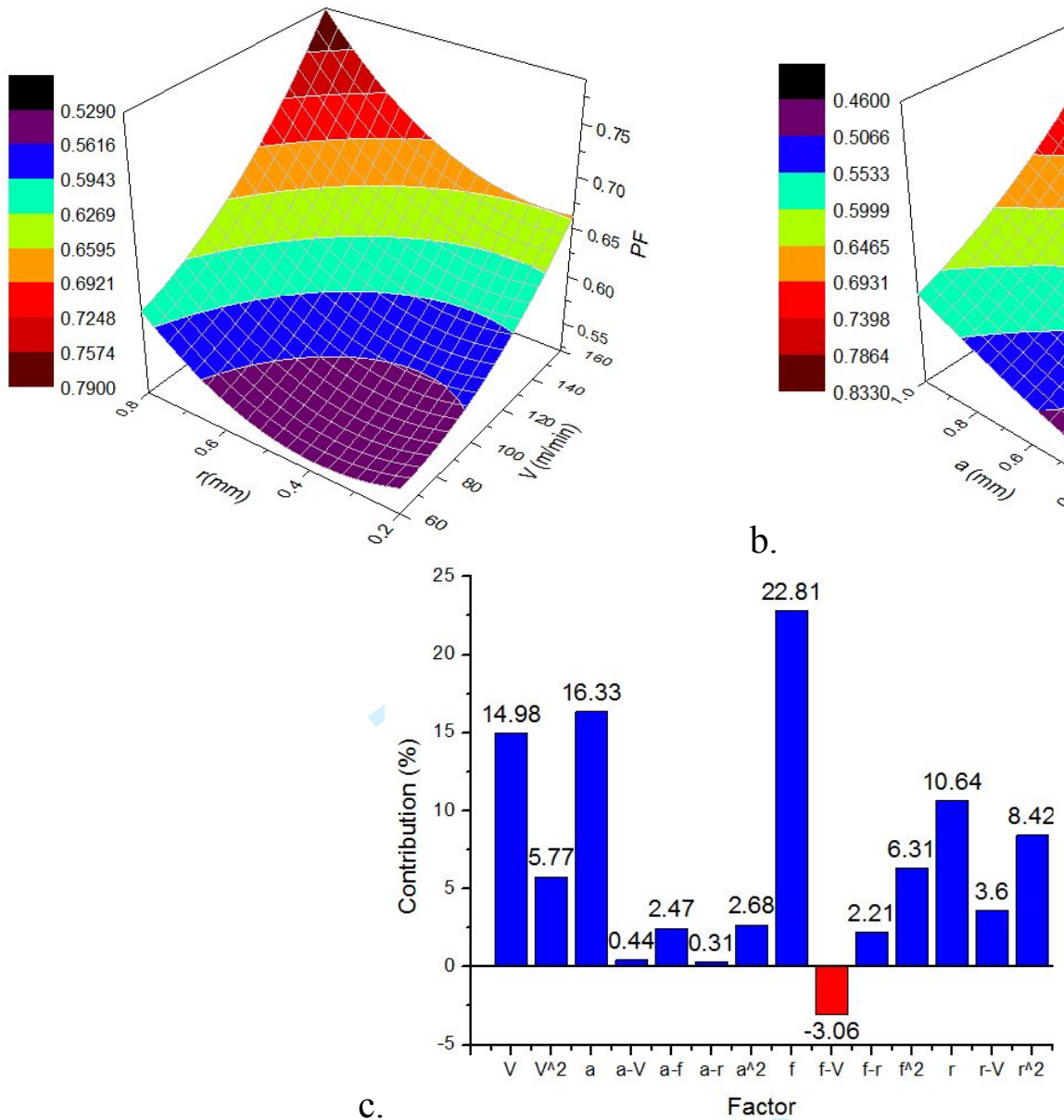

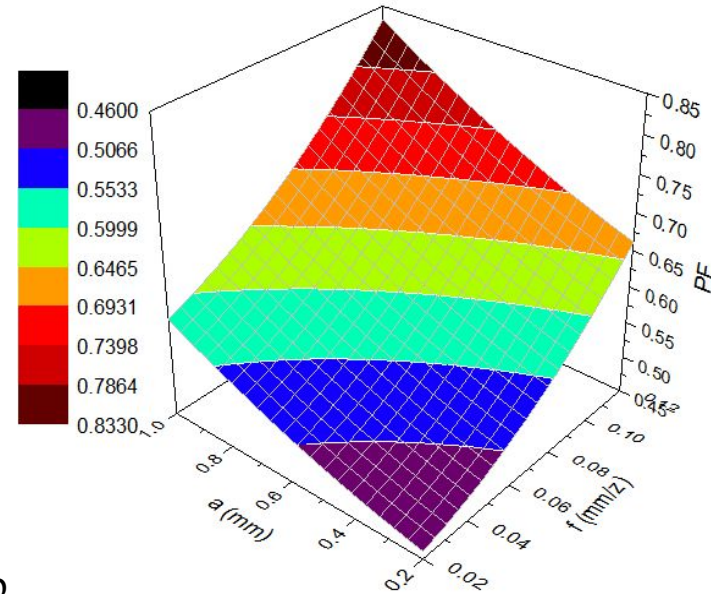

b.

Figure 9. The effects of machining parameters on the PF model: (a) PF versus V and $r$, (b) PF versus a and f, (c) Parameter contributions for the PF model 

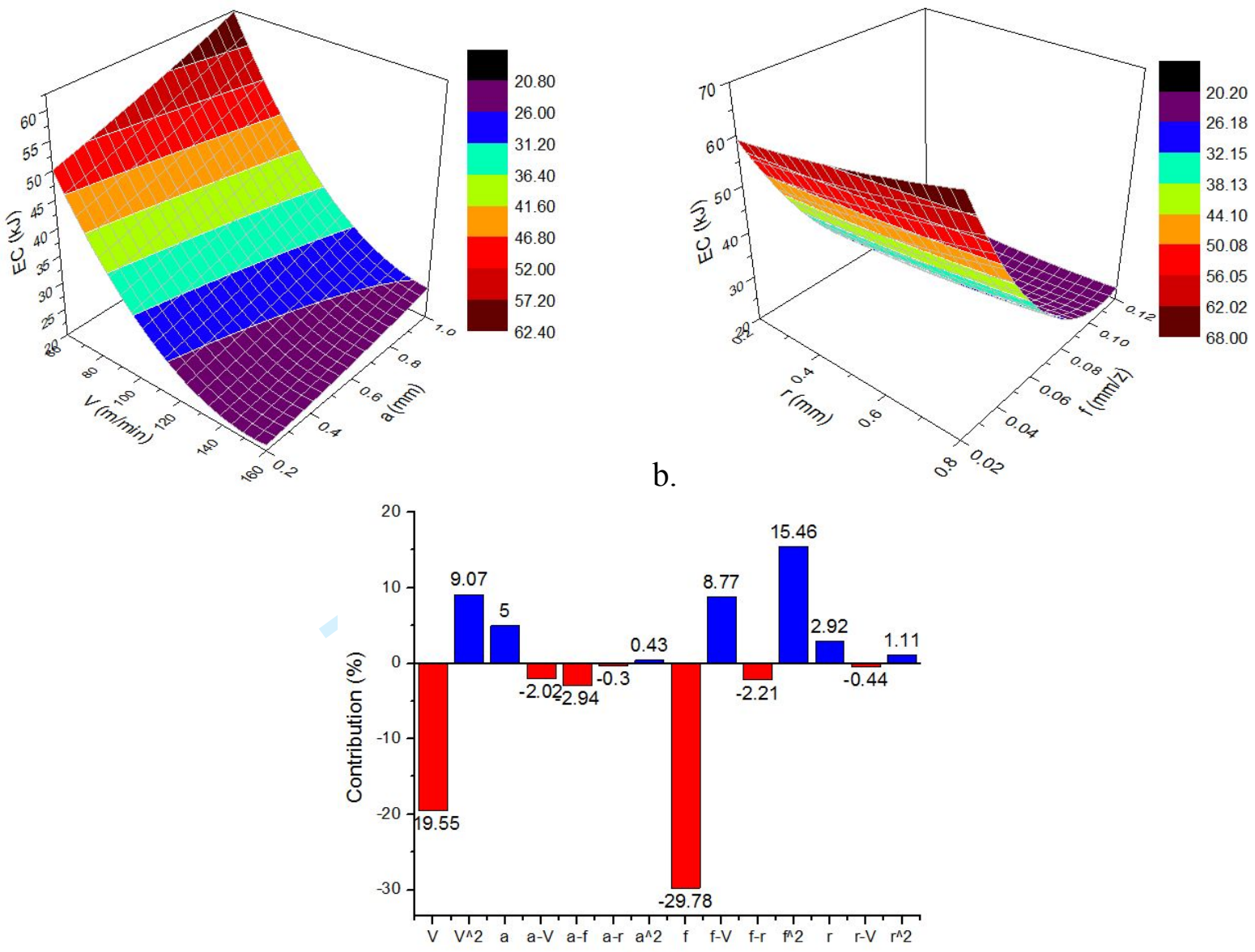

c.

Figure 10. The effects of machining parameters on the EC model: (a) EC versus $\mathrm{V}$ and a, (b) EC versus $r$ and f, (c) Parameter contributions for the EC model 
a.
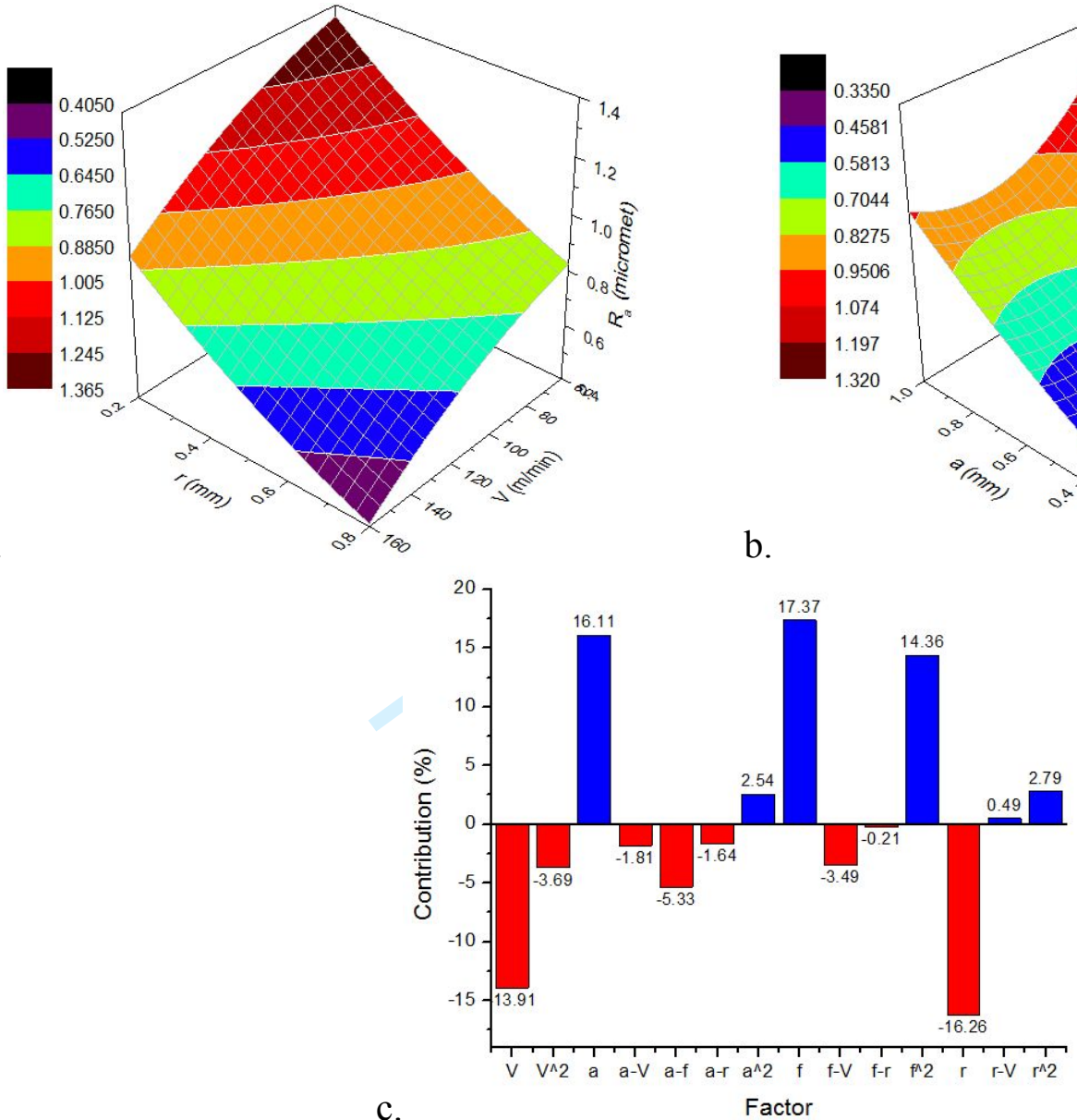

Figure 11. Interaction effects of machining parameters on the $R_{a}$ model: (a) $R_{a}$ versus $r$ and $V$, (b) $R_{a}$ versus f and a, (c) Parameter contributions on the $R_{a}$ model 

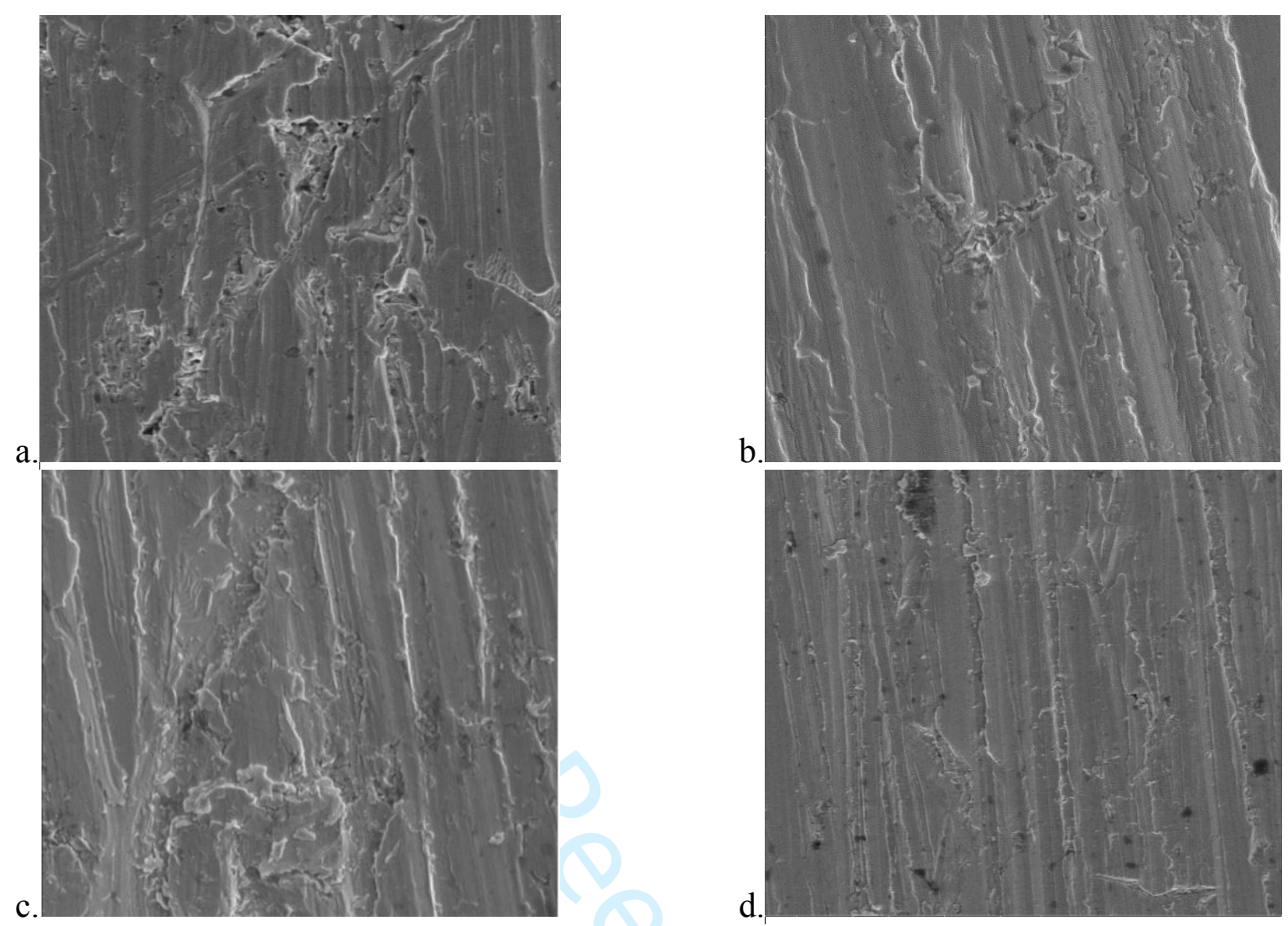

Figure 12. SEM of surface morphology at various conditions: (a) Experiment no. 4, (b) Experiment no.12, (c) Experiment no.1, (d) Experiment no. 7
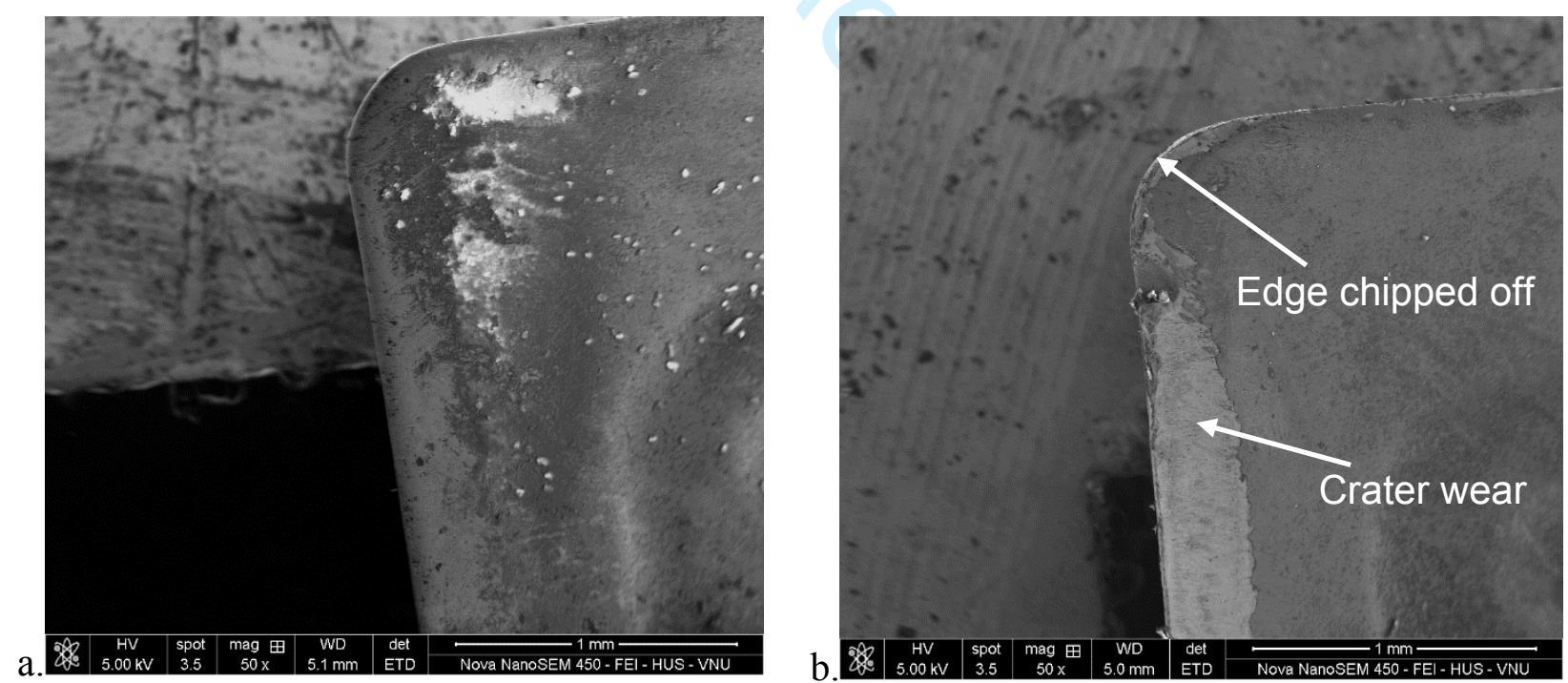

Figure 13. SEM images of the worn tool's rake surface at various machining conditions: (a) Experiment no. 16, (b) Experiment no. 20 


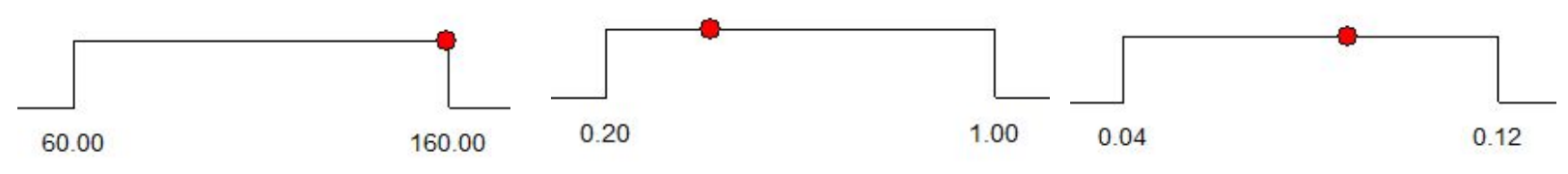

$\begin{array}{lll}\text { Cutting speed } V=160.00 & \text { Depth of cut } a=0.42 & \text { Feed rate } f=0.09\end{array}$

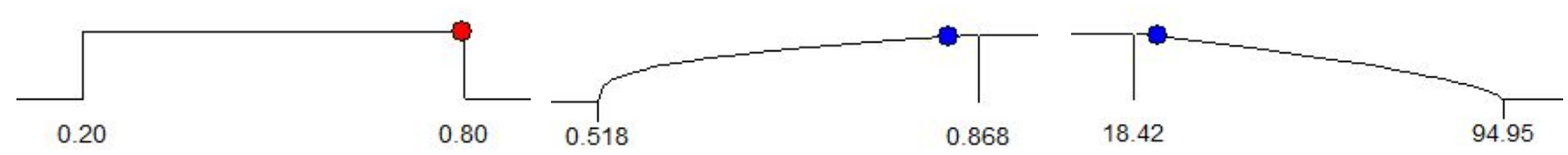

$\begin{array}{lll}\text { Radius }=0.80 & \mathrm{PF}=0.840 \quad \mathrm{EC}=23.56\end{array}$

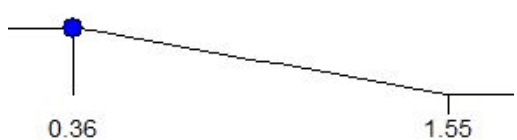

a.

$\mathrm{Ra}=0.36$

b.

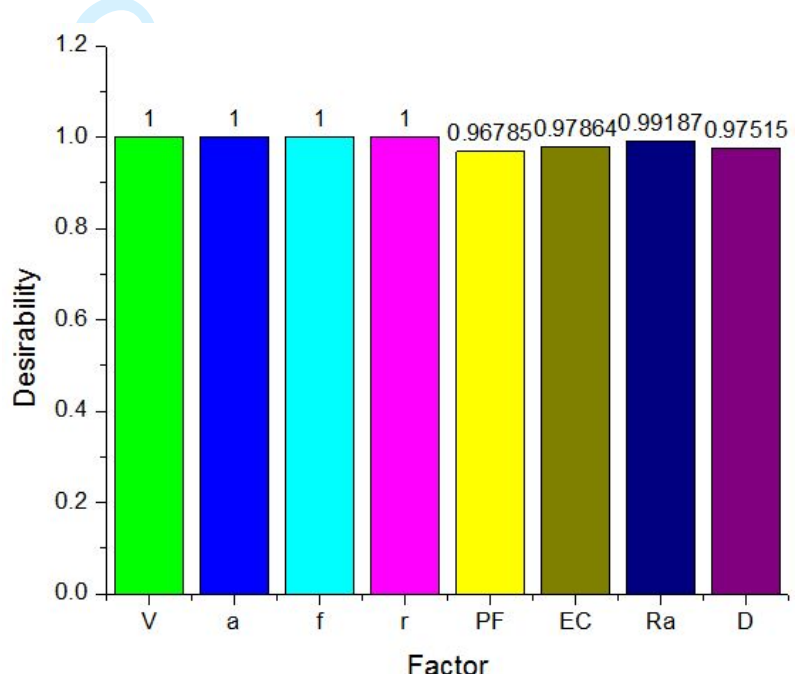

Figure 14. Optimization results generated by DA: (a) Optimal values, (b) Bar graph of the desirability 
b.
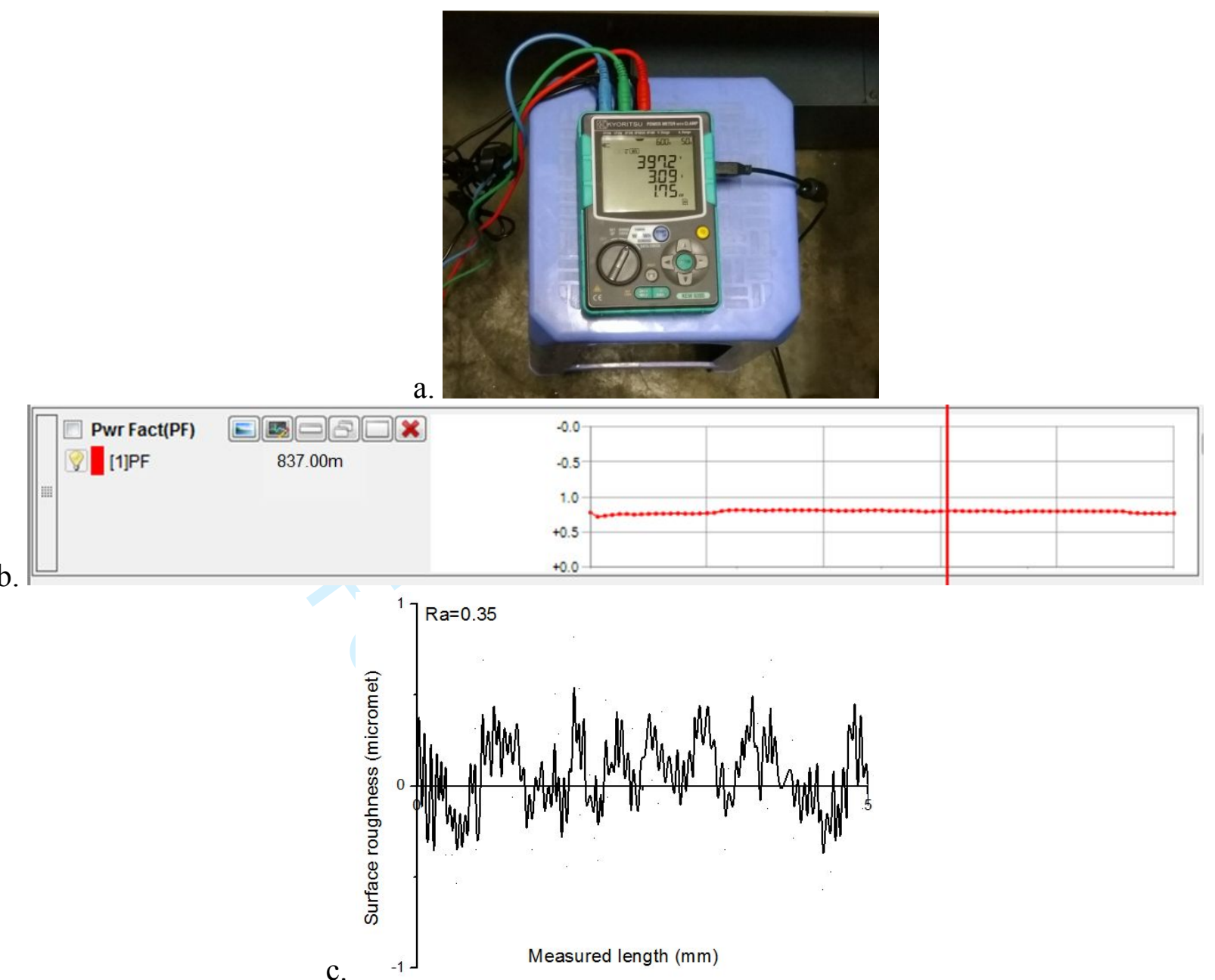

Figure 15. Experimental results at the optimal solution: (a) Power consumed, (b) Power factor, (c) Surface roughness 


\section{List of Tables}

Table 1. Processing conditions

Table 2. Experimental results

Table 3. The values of evaluating criteria

Table 4. Pre-processed and deviation results

Table 5. Values of grey relational coefficients (GRC)

Table 6. Eigenvalues and proportions of the principal components

Table 7. Eigenvectors and contributions for the principal components

Table 8. Optimization results

Table 9. Results of confirmatory experiment 
Table 1. Processing conditions

\begin{tabular}{|c|c|c|c|c|}
\hline Symbol & Parameters & level-1 & level 0 & level +1 \\
\hline $\mathrm{V}$ & Cutting speed $(\mathrm{m} / \mathrm{min})$ & 60 & 110 & 160 \\
\hline $\mathrm{a}$ & Depth of cut $(\mathrm{mm})$ & 0.2 & 0.6 & 1.0 \\
\hline $\mathrm{f}$ & Feed rate $(\mathrm{mm} / \mathrm{z})$ & 0.04 & 0.08 & 0.12 \\
\hline $\mathrm{r}$ & Nose radius $(\mathrm{mm})$ & 0.2 & 0.4 & 0.8 \\
\hline
\end{tabular}

Table 2. Experimental results

\begin{tabular}{|c|c|c|c|c|c|c|c|}
\hline No. & $\begin{array}{l}\text { Cutting speed } \\
\mathrm{V}(\mathrm{m} / \mathrm{min})\end{array}$ & $\begin{array}{l}\text { Depth of cut } \\
\text { a (mm) }\end{array}$ & $\begin{array}{l}\text { Feed rate } \\
\mathrm{f}(\mathrm{mm} / \mathrm{z})\end{array}$ & $\begin{array}{l}\text { Nose radius } \\
\quad \mathrm{r}(\mathrm{mm})\end{array}$ & $\begin{array}{c}\text { Power factor } \\
\text { PF }\end{array}$ & $\begin{array}{c}\text { Energy } \\
\text { consumption } \\
\text { EC }(\mathrm{kJ}) \\
\end{array}$ & $\begin{array}{c}\text { Surface } \\
\text { roughness } \\
\mathrm{R}_{\mathrm{a}}(\mu \mathrm{m}) \\
\end{array}$ \\
\hline 1 & 110 & 0.2 & 0.04 & 0.4 & 0.518 & 50.33 & 0.45 \\
\hline 2 & 110 & 0.6 & 0.12 & 0.8 & 0.867 & 25.46 & 1.08 \\
\hline 3 & 110 & 0.6 & 0.08 & 0.4 & 0.652 & 31.56 & 0.85 \\
\hline 4 & 60 & 0.6 & 0.08 & 0.2 & 0.611 & 53.66 & 1.34 \\
\hline 5 & 160 & 0.6 & 0.12 & 0.4 & 0.851 & 18.42 & 0.95 \\
\hline 6 & 60 & 0.6 & 0.12 & 0.4 & 0.736 & 42.6 & 1.47 \\
\hline 7 & 110 & 0.2 & 0.12 & 0.4 & 0.690 & 21.99 & 1.14 \\
\hline 8 & 60 & 0.6 & 0.08 & 0.8 & 0.685 & 59.13 & 0.78 \\
\hline 9 & 60 & 1.0 & 0.08 & 0.4 & 0.703 & 61.68 & 1.31 \\
\hline 10 & 110 & 1.0 & 0.12 & 0.4 & 0.868 & 26.72 & 1.49 \\
\hline 11 & 110 & 1.0 & 0.08 & 0.2 & 0.732 & 35.41 & 1.42 \\
\hline 12 & 160 & 0.6 & 0.08 & 0.2 & 0.719 & 22.84 & 0.89 \\
\hline 13 & 160 & 1.0 & 0.08 & 0.4 & 0.835 & 27.26 & 0.79 \\
\hline 14 & 60 & 0.2 & 0.08 & 0.4 & 0.547 & 48.96 & 0.82 \\
\hline 15 & 160 & 0.6 & 0.04 & 0.4 & 0.690 & 44.62 & 0.47 \\
\hline 16 & 110 & 0.6 & 0.04 & 0.2 & 0.566 & 54.03 & 0.98 \\
\hline 17 & 60 & 0.6 & 0.04 & 0.4 & 0.529 & 94.95 & 0.82 \\
\hline 18 & 110 & 1.0 & 0.04 & 0.4 & 0.659 & 63.82 & 1.06 \\
\hline 19 & 160 & 0.2 & 0.08 & 0.4 & 0.671 & 22.07 & 0.41 \\
\hline 20 & 110 & 0.6 & 0.12 & 0.2 & 0.752 & 23.74 & 1.55 \\
\hline 21 & 110 & 0.6 & 0.04 & 0.8 & 0.648 & 62.35 & 0.52 \\
\hline 22 & 160 & 0.6 & 0.08 & 0.8 & 0.862 & 26.68 & 0.36 \\
\hline 23 & 110 & 0.2 & 0.08 & 0.2 & 0.576 & 28.23 & 0.91 \\
\hline 24 & 110 & 0.2 & 0.08 & 0.8 & 0.681 & 32.95 & 0.48 \\
\hline 25 & 110 & 1.0 & 0.08 & 0.8 & 0.843 & 39.02 & 0.89 \\
\hline 26 & 80 & 0.4 & 0.06 & 0.4 & 0.533 & 53.50 & 0.45 \\
\hline 27 & 100 & 0.8 & 0.02 & 0.4 & 0.563 & 86.83 & 1.08 \\
\hline 28 & 130 & 0.5 & 0.10 & 0.8 & 0.817 & 22.98 & 0.85 \\
\hline 29 & 150 & 0.9 & 0.05 & 0.2 & 0.712 & 39.61 & 1.34 \\
\hline
\end{tabular}


Table 3. The values of evaluating criteria

\begin{tabular}{|c|c|c|c|c|}
\hline Responses & $\mathrm{R}^{2}$ & RMSE & MEA & AAE \\
\hline $\mathrm{PF}$ & 0.9954 & 0.0049 & 0.0152 & 0.0032 \\
\hline $\mathrm{EC}$ & 0.9921 & 0.0076 & 0.0178 & 0.0046 \\
\hline $\mathrm{R}_{\mathrm{a}}$ & 0.9938 & 0.0064 & 0.0166 & 0.0039 \\
\hline
\end{tabular}

Table 4. Pre-processed and deviation results

\begin{tabular}{|c|c|c|c|c|c|c|}
\hline \multirow{2}{*}{ No. } & \multicolumn{3}{|c|}{ Pre-processed data $\mathrm{x}_{\mathrm{i}}(\mathrm{k})$} & \multicolumn{3}{c|}{ Deviation sequences $\Delta_{0 \mathrm{i}}(\mathrm{k})$} \\
\cline { 2 - 7 } & $\begin{array}{c}\text { Power factor } \\
\mathrm{PF}\end{array}$ & $\begin{array}{c}\text { Energy consumption } \\
\text { EC }\end{array}$ & $\begin{array}{c}\text { Surface } \\
\text { roughness } \\
\mathrm{R}_{\mathrm{a}}\end{array}$ & $\begin{array}{c}\text { Power factor } \\
\mathrm{PF}\end{array}$ & $\begin{array}{c}\text { Energy consumption } \\
\text { EC }\end{array}$ & $\begin{array}{c}\text { Surface } \\
\text { roughness } \\
\mathrm{R}_{\mathrm{a}}\end{array}$ \\
\hline 1 & 0.00 & 0.58 & 0.92 & 1.00 & 0.42 & 0.08 \\
\hline 2 & 1.00 & 0.91 & 0.39 & 0.00 & 0.09 & 0.61 \\
\hline 3 & 0.38 & 0.83 & 0.59 & 0.62 & 0.17 & 0.41 \\
\hline 4 & 0.27 & 0.54 & 0.18 & 0.73 & 0.46 & 0.82 \\
\hline 5 & 0.95 & 1.00 & 0.50 & 0.05 & 0.00 & 0.50 \\
\hline 6 & 0.62 & 0.68 & 0.07 & 0.38 & 0.32 & 0.93 \\
\hline 7 & 0.49 & 0.95 & 0.34 & 0.51 & 0.05 & 0.66 \\
\hline 8 & 0.48 & 0.47 & 0.65 & 0.52 & 0.53 & 0.35 \\
\hline 9 & 0.53 & 0.43 & 0.20 & 0.47 & 0.57 & 0.80 \\
\hline 10 & 1.00 & 0.89 & 0.05 & 0.00 & 0.11 & 0.95 \\
\hline 11 & 0.61 & 0.78 & 0.11 & 0.39 & 0.22 & 0.89 \\
\hline 12 & 0.57 & 0.94 & 0.55 & 0.43 & 0.06 & 0.45 \\
\hline 13 & 0.91 & 0.88 & 0.64 & 0.09 & 0.12 & 0.36 \\
\hline 14 & 0.08 & 0.60 & 0.61 & 0.92 & 0.40 & 0.39 \\
\hline 15 & 0.49 & 0.66 & 0.91 & 0.51 & 0.34 & 0.09 \\
\hline 16 & 0.14 & 0.53 & 0.48 & 0.86 & 0.47 & 0.52 \\
\hline 17 & 0.03 & 0.00 & 0.61 & 0.97 & 1.00 & 0.39 \\
\hline 18 & 0.40 & 0.41 & 0.41 & 0.60 & 0.59 & 0.59 \\
\hline 19 & 0.44 & 0.95 & 0.96 & 0.56 & 0.05 & 0.04 \\
\hline 20 & 0.67 & 0.93 & 0.00 & 0.33 & 0.07 & 1.00 \\
\hline 21 & 0.37 & 0.43 & 0.87 & 0.63 & 0.57 & 0.13 \\
\hline 22 & 0.98 & 0.89 & 1.00 & 0.02 & 0.11 & 0.00 \\
\hline 23 & 0.17 & 0.87 & 0.54 & 0.83 & 0.13 & 0.46 \\
\hline 24 & 0.47 & 0.81 & 0.90 & 0.53 & 0.19 & 0.10 \\
\hline 25 & 0.93 & 0.73 & 0.55 & 0.07 & 0.27 & 0.45 \\
\hline
\end{tabular}


Table 5. Values of grey relational coefficients (GRC)

\begin{tabular}{|c|c|c|c|}
\hline \multirow[t]{2}{*}{ No. } & \multicolumn{3}{|c|}{ Grey relation coefficient } \\
\hline & $\begin{array}{c}\text { Power factor } \\
\text { PF }\end{array}$ & $\begin{array}{c}\text { Energy consumption } \\
\text { EC }\end{array}$ & $\begin{array}{c}\text { Surface roughness } \\
\mathrm{R}_{\mathrm{a}}\end{array}$ \\
\hline 1 & 0.33 & 0.55 & 0.87 \\
\hline 2 & 1.00 & 0.84 & 0.45 \\
\hline 3 & 0.45 & 0.74 & 0.55 \\
\hline 4 & 0.41 & 0.52 & 0.38 \\
\hline 5 & 0.91 & 1.00 & 0.50 \\
\hline 6 & 0.57 & 0.61 & 0.35 \\
\hline 7 & 0.50 & 0.91 & 0.43 \\
\hline 8 & 0.49 & 0.48 & 0.59 \\
\hline 9 & 0.51 & 0.47 & 0.39 \\
\hline 10 & 1.00 & 0.82 & 0.34 \\
\hline 11 & 0.56 & 0.69 & 0.36 \\
\hline 12 & 0.54 & 0.90 & 0.53 \\
\hline 13 & 0.84 & 0.81 & 0.58 \\
\hline 14 & 0.35 & 0.56 & 0.56 \\
\hline 15 & 0.50 & 0.59 & 0.84 \\
\hline 16 & 0.37 & 0.52 & 0.49 \\
\hline 17 & 0.34 & 0.33 & 0.56 \\
\hline 18 & 0.46 & 0.46 & 0.46 \\
\hline 19 & 0.47 & 0.91 & 0.92 \\
\hline 20 & 0.60 & 0.88 & 0.33 \\
\hline 21 & 0.44 & 0.47 & 0.79 \\
\hline 22 & 0.96 & 0.82 & 1.00 \\
\hline 23 & 0.37 & 0.80 & 0.52 \\
\hline 24 & 0.48 & 0.72 & 0.83 \\
\hline 25 & 0.87 & 0.65 & 0.53 \\
\hline
\end{tabular}

Table 6. Eigenvalues and proportions of the principal components

\begin{tabular}{|c|c|c|}
\hline Principal component & Eigen values & Proportion (\%) \\
\hline First & 1.5614 & 52.00 \\
\hline Second & 0.9973 & 33.20 \\
\hline Third & 0.4412 & 14.70 \\
\hline
\end{tabular}

Table 7. Eigenvectors and contributions for the principal components

\begin{tabular}{|c|c|c|c|c|}
\hline \multirow{2}{*}{ Characteristics } & \multicolumn{3}{|c|}{ Eigenvectors } & Weight \\
\cline { 2 - 4 } & $\begin{array}{c}\text { The first principal } \\
\text { component }\end{array}$ & $\begin{array}{c}\text { The second principal } \\
\text { component }\end{array}$ & $\begin{array}{c}\text { The third principal } \\
\text { component }\end{array}$ & value \\
\hline PF & 0.706 & 0.013 & -0.708 & 0.32 \\
\hline EC & 0.695 & 0.179 & 0.696 & 0.35 \\
\hline $\mathrm{R}_{\mathrm{a}}$ & -0.135 & 0.984 & -0.117 & 0.33 \\
\hline
\end{tabular}


Table 8. Optimization results

\begin{tabular}{|c|c|c|c|c|c|c|c|}
\hline \multirow{2}{*}{ Method } & \multicolumn{3}{|c|}{ Optimization parameters } & \multicolumn{3}{c|}{ Responses } \\
\cline { 2 - 8 } & $\begin{array}{c}\text { Cutting } \\
\text { speed } \\
\mathrm{V} \\
(\mathrm{m} / \mathrm{min})\end{array}$ & $\begin{array}{c}\text { Depth } \\
\text { of cut } \\
\mathrm{a} \\
(\mathrm{mm})\end{array}$ & $\begin{array}{c}\text { Feed } \\
\text { rate } \\
\mathrm{f} \\
(\mathrm{mm} / \mathrm{z})\end{array}$ & $\begin{array}{c}\text { Nose } \\
\text { radius } \\
\mathrm{r}(\mathrm{mm})\end{array}$ & $\begin{array}{c}\text { Power } \\
\text { factor } \\
\mathrm{PF}\end{array}$ & $\begin{array}{c}\text { Energy } \\
\text { consumption } \\
\text { EC }(\mathrm{kJ})\end{array}$ & $\begin{array}{c}\text { Surface } \\
\text { roughness } \\
\mathrm{R}_{\mathrm{a}}(\mu \mathrm{m})\end{array}$ \\
\hline Initial & 110 & 0.60 & 0.08 & 0.4 & 0.652 & 31.56 & 0.85 \\
\hline DA & 160 & 0.42 & 0.09 & 0.8 & 0.840 & 20.56 & 0.36 \\
\hline Improvement (\%) & & & & & 28.83 & -34.85 & -57.65 \\
\hline
\end{tabular}

Table 9. Results of confirmatory experiment

\begin{tabular}{|c|c|c|c|c|}
\hline \multirow{2}{*}{ Method } & \multicolumn{4}{|c|}{ Responses } \\
\cline { 2 - 5 } & $\begin{array}{c}\text { Power factor } \\
\mathrm{PF}\end{array}$ & $\begin{array}{c}\text { Power } \\
\text { consumption } \\
\mathrm{P}_{\mathrm{c}}(\mathrm{W})\end{array}$ & $\begin{array}{c}\text { Energy } \\
\text { consumption } \\
\mathrm{EC}(\mathrm{kJ})\end{array}$ & $\begin{array}{c}\text { Surface } \\
\text { roughness } \\
\mathrm{R}_{\mathrm{a}}(\mu \mathrm{m})\end{array}$ \\
\hline DA & 0.840 & 1746 & 20.56 & 0.36 \\
\hline Confirmatory experiment & 0.836 & 1752 & 20.63 & 0.35 \\
\hline Error (\%) & 0.48 & 0.34 & 0.34 & 2.78 \\
\hline
\end{tabular}

